\title{
PHASE SEPARATION TO CREATE HYDROPHILIC YET NON-WATER SOLUBLE PLA/PLA-b-PEG FIBERS VIA ELECTROSPINNING
}

\author{
A Thesis \\ Presented to the Faculty of the Graduate School \\ of Cornell University \\ in Partial Fulfillment of the Requirements for the Degree of \\ Masters of Science
}

by

Larissa M. Buttaro

May 2013 
(C) 2013 Larissa M. Buttaro 


\begin{abstract}
The goal of this research is to use polymer phase separation to create biocompatible, biodegradable, and sustainable fibers that are hydrophilic yet non-water soluble by electrospinning from homogeneous solutions. Currently, fiber-forming polymeric materials are largely hydrophobic or water-soluble, which limits their usefulness in biological system applications and in aqueous environments. In this study, Poly(lactic acid)(PLA) and block copolymers: PLA-b-Poly(ethylene glycol) (PLA-b-PEG), were co-dissolved in dimethylformamide (DMF) and electrospun into nanofibers. PLA and PEG have minimal miscibility and will phase separate. The influence of PLA-b-PEG block lengths and block length ratios on the total quantity of PEG that could be incorporated into the fibers, the morphology and phases formed in the fiber and the hydrophilicty of non-woven fabrics was investigated. Based upon previous research, PLA(5000)-b-PEG(1000), PLA(1000)-b-PEG(5000), PLA(1000)-b-PEG(10000), and PLA(2000)-b-PEG (5000)-N3 were chosen for the varying block lengths. With the exception of PLA(5000)-b-PEG(1000), loadings higher than 10wt\% PEG could be incorporated into the electrospun fibers by the addition of a heating element and heat gun. With the addition of PLAb-PEG, fiber diameter decreased significantly when compared to that of the control PLA fibers. For the copolymers, the melting temperature of PEG was consistently seen when PEG content was greater than $10 \mathrm{wt} \%$, indicating phase separation. The addition of PEG or PLA-b-PEG to the fibers decreased the glass transition and cold crystallization temperatures, confirming PEG was plasticizing and aiding in the crystallization of the PLA. XPS and FTIR analysis of PLA(2000)b-PEG(5000)-N3 showed no sign of -N3; it was concluded -N3 was not in the samples. Swelling test prove that with the addition of PEG or PLA-b-PEG to PLA, fibers were non-water soluble. With increasing content of PEG from PLA-b-PEG, water wicking is increased until
\end{abstract}


rheological affects dominate. As PEG chain length is increased, the amount of water wicked increases. The amount of water wicked was a combination of PEG wt $\%$ and block length. With increasing $\mathrm{wt} \%$ PEG and block length, the amount of PEG reaching the fiber surface was found to increase thus resulting in greater wicking ability. 


\section{BIOGRAPHICAL SKETCH}

Larissa Buttaro was born in Rochester NY and received her B.S. in Materials Science and Engineering from the SUNY College of Ceramics at Alfred University. She began her studies in Fiber Science at Cornell University in 2011. Her research interests are in the creation of fiber systems for capture and detection of contaminates. 
Dedicated to my family and friends 


\section{ACKNOWLEDGMENTS}

I would like to express my overwhelming thanks to a number of individuals both in Ithaca, NY and Rochester, NY, without whom this accomplishment would not have been achieved. Firstly, I would like to thank my advisor, Professor Margaret Frey, for not only her support, and guidance, but also her encouragement. I would also like to thank my minor advisor, Professor Christopher Ober from the Department of Materials Science and Engineering.

Next I would like to thank the entire faculty and staff of the Department of Fiber Science \& Apparel Design for all of their support, advice, and assistance. A big thanks goes to Professor Chunhui Xiang, and Professor Erin Hendrick for all of their previous research and guidance. Thanks also goes to my undergraduate research assistant, Erin Durfva,, who assisted in collecting experimental data.

Lastly, I would like to give a huge thanks to my family and friends. To my parents and brothers, thank you for all of your love and support. To the office girls, thank you for keeping me grounded, and not constantly in the lab. 
TABLE OF CONTENTS

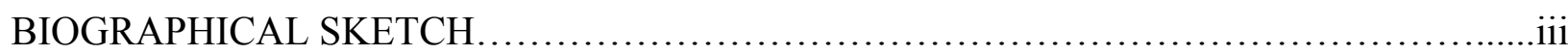

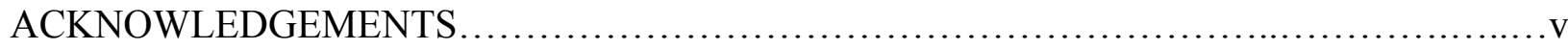

LIST OF FIGURES.........................................................................

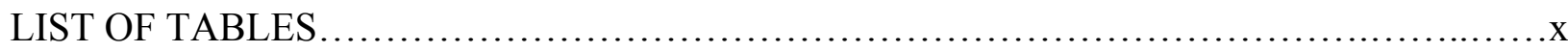

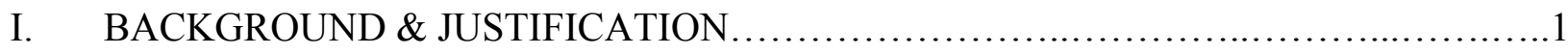

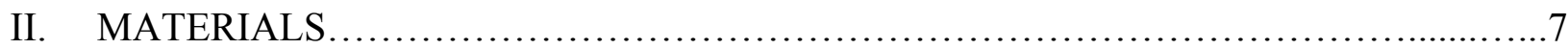

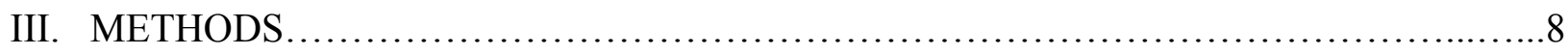

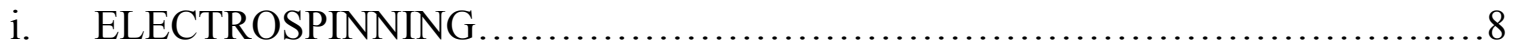

ii. SCANNING ELECTRON MICROSCOPY(SEM) ..................................9

iii. DIFFERENTIAL SCANNING CALORIMETRY(DSC)...........................10

iv. X-RAY PHOTOELECTRON SPECTROSCOPY (XPS) ...........................10

v. FOURIER TRANSFORMATION INFARED SPECTROSCOPY(FTIR) ............10

vi. TIME-OF-FLIGHT SECONDARY ION MASS SPECTROMETRY

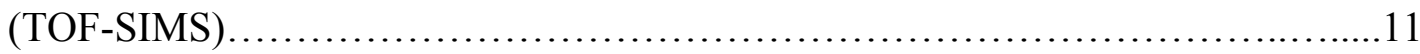

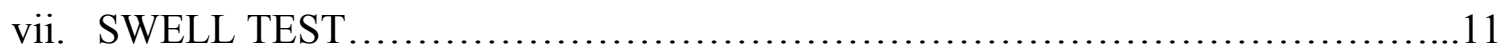

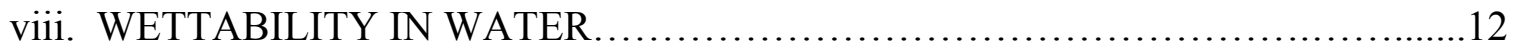

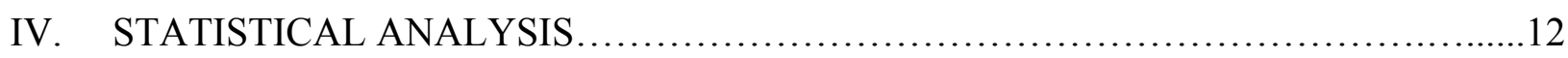

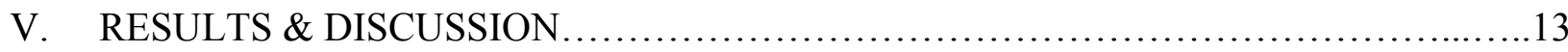

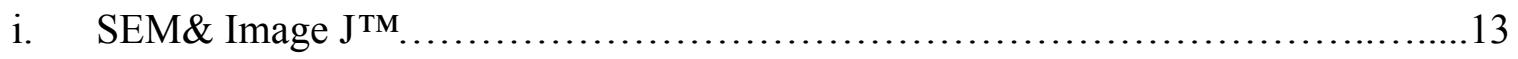

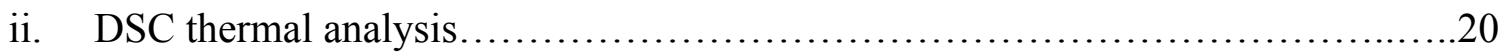

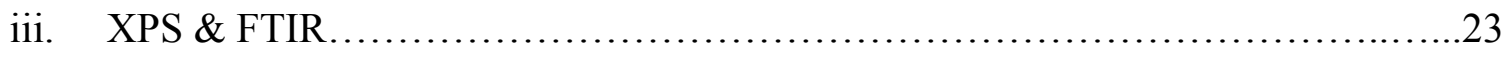

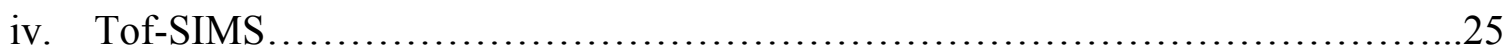




\section{PAGE}

v. Swelling Comparisons................................................27

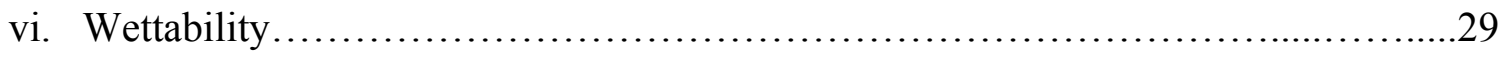

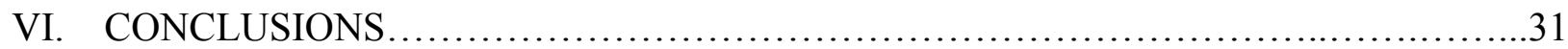

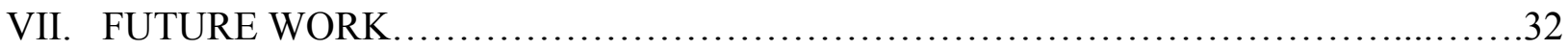

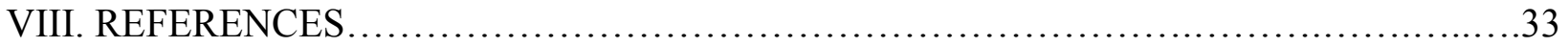


FIGURE 1. An electrospinning apparatus..............................................

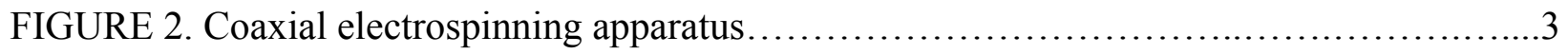

FIGURE 3. Phase separation of two polymers dissolved in solvent...........................

FIGURE 4. PLA and PEG chemical structures...........................................

FIGURE 5. Fiber produced by phase separation during electrospinning .......................6

FIGURE 6. E. Hendrick et al. wettabllity data for PLA, and PLA-b-PEG electrospun fibers.......7

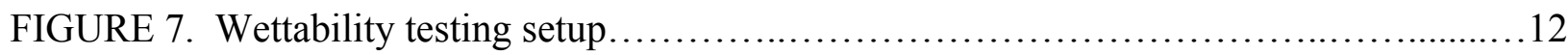

FIGURE 8. SEM images of : A) 100wt\%PLA fiber. B) 4wt\% PEG from PLA(5000)-bPEG(1000) fiber. C) $5 \mathrm{wt} \%$ PEG from PLA(5000)-b-PEG(1000) fiber. D) $6 \mathrm{wt} \%$ PEG from

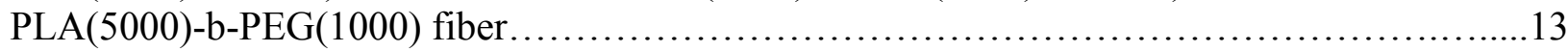

FIGURE 9. SEM images of : A) 100wt $\%$ PLA fiber. B) $5 \mathrm{wt} \%$ PEG fiber. C) $10 \mathrm{wt} \%$ PEG fiber. D) $12 \mathrm{wt} \%$ PEG fiber. E) $14 \mathrm{wt} \%$ PEG fiber. F) $16 \mathrm{wt} \%$ PEG fiber.........................15

FIGURE 10. SEM images of : A) 100wt\%PLA fiber. B) 5wt\% PEG from PLA(1000)-bPEG(5000) fiber. C) $10 \mathrm{wt} \%$ PEG from PLA(1000)-b-PEG(5000) fiber. D) $12 \mathrm{wt} \%$ PEG from PLA(1000)-b-PEG(5000) fiber. E) 14wt\% PEG from PLA(1000)-b-PEG(5000) fiber.

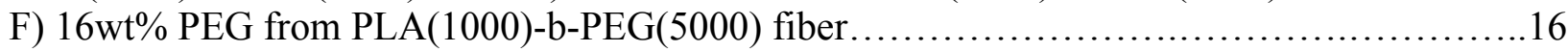

FIGURE 11. SEM images of : A) 100wt\%PLA fiber. B) 5wt\% PEG from PLA(1000)-bPEG(10000) fiber. C) $10 \mathrm{wt} \%$ PEG from PLA(1000)-b-PEG(10000) fiber. D) $12 \mathrm{wt} \%$ PEG from PLA(1000)-b-PEG(10000) fiber. E) 14wt \% PEG from PLA(1000)-b-PEG(10000) fiber.

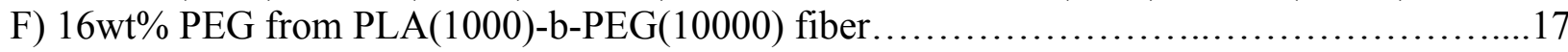

FIGURE 12. Comparison of average diameters........................................ 18

FIGURE 13. SEM PEG from PLA(1000)-b-PEG(10000) where it is seen that in some areas there is fiber non-uniformity. (A) SEM image of $12 \mathrm{wt} \%$. (B) SEM image of $14 \mathrm{wt} \%$.

(C) SEM image of $16 \mathrm{wt} \%$

FIGURE 14. Tc and Tg data trends with increasing PEG content...........................20

FIGURE 15. (A) Melting temperatures observed for PEG in various electrospun fibers. (B) Melting temperatures observed for PLA for various electrospun fibers fibers. 
PAGE

FIGURE 16. (A) DSC $1^{\text {st }}$ heating scan. (B) DSC scan after the fibers have been cooled and re-heated $\left(2^{\text {nd }}\right.$ heating). The DSC results have had a factor added for clarity of graphs.....

FIGURE 17. Heat-cool-heat DSC data for (A) $0 \mathrm{wt} \% \mathrm{PEG}$ and (B) $12 \mathrm{wt} \% \mathrm{PEG}$ from

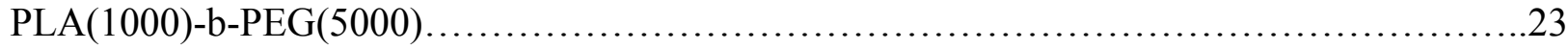

FIGURE 18. XPS data for 0wt \% PEG fibers and 12wt $\%$ PEG from PLA(2200)-b-

PEG(5000) -N3 fibers

FIGURE 19. FTIR data for 0wt\%PEG, PLA/PLA-b-PEG, and PLA/PLA-b-PEG-N3

fibers. .25

FIGURE 20. Tof-SIMS data collection. (A) PEG(6000) powder (B) 0wt\%PEG fibers (100wt\%PLA), (C) 14wt\%PEG from PLA(1000)-b-PEG(5000) fibers. .26

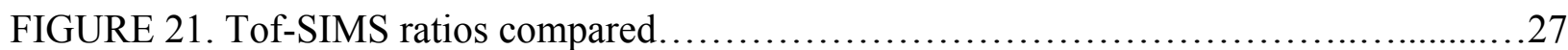

FIGURE 22. Pictures and SEM images taken post swelling test..........................28

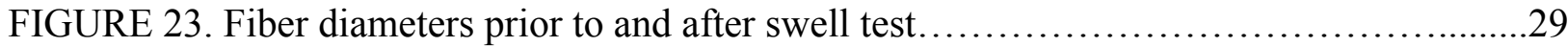

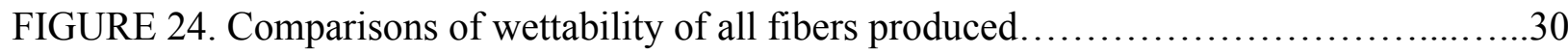


TABLE 1.Final fiber content using various solutions................................... 


\section{Background \& Justification}

Biosensors, tissue scaffolds, filtration membranes, and protective clothing are continually investigated for improvements in size and functionality.[1-4] Features that have been identified as desirable include submicron dimensions of solid and pore regions, surface hydrophilicity, specific surface functionality and biocompatibility. Nanofibrous membranes in particular combine high surface area, high porosity $[5,6]$ and can be produced from a broad range of biocompatible and functional materials[7-20]. In the work reported here, Poly(lactic acid) (PLA), a biodegradable, biocompatible, hydrophobic polymer, is blended with PLA-b-PEG copolymers with a goal of increasing hydrophilicity of the membrane surfaces.

Poly(lactic acid) is a biodegradable, biocompatible material that can be readily electrospun to form uniform nanofibers and nonwoven fabrics.[21] Several researchers have explored modifying PLA for specific uses by adding active ingredients to the electrospinning dope $[5,8$, 10, 22-26], co-axial electrospinning[23, 27-30] or post-spinning modification techniques[31, 32]. Materials added to the PLA electrospinning dope have been shown to phase separate during the electrospinning process to create a responsive core[13] or enriched surface on the fibers[10, 33, 34]. Adding a less hydrophobic polymer to PLA can modify the hydrophobic surface properties

of PLA.[33-36] The research reported here strives to determine the optimum proportions and block lengths of PLA-b-PEG necessary to maximize migration of PEG to the electrospun fiber surface and hydrophilicity of the resulting nonwoven fabrics. By integrating the PLA with the PLA-b-PEG this study seeks to create a hydrophilic, yet non-water soluble fiber. 
Electrospinning is the application of a high electric field to overcome the surface tension of a polymer solution that produces nano to micro scaled fibers on a grounded collector.[3] Over the past decade, many modifications have been made to the basic electrospinning system to achieve specific structures or increase throughput. The electrospinning apparatus used in this research is shown in Figure 1. A temperature controlled heating chamber was added to house the syringe. Additionally, a heating gun was incorporated to keep the needle tip at an elevated temperature necessary for electrospinning. Other modifications include coaxial spinning to achieve sheath/core structures and needle-less electrospinning for higher throughput.

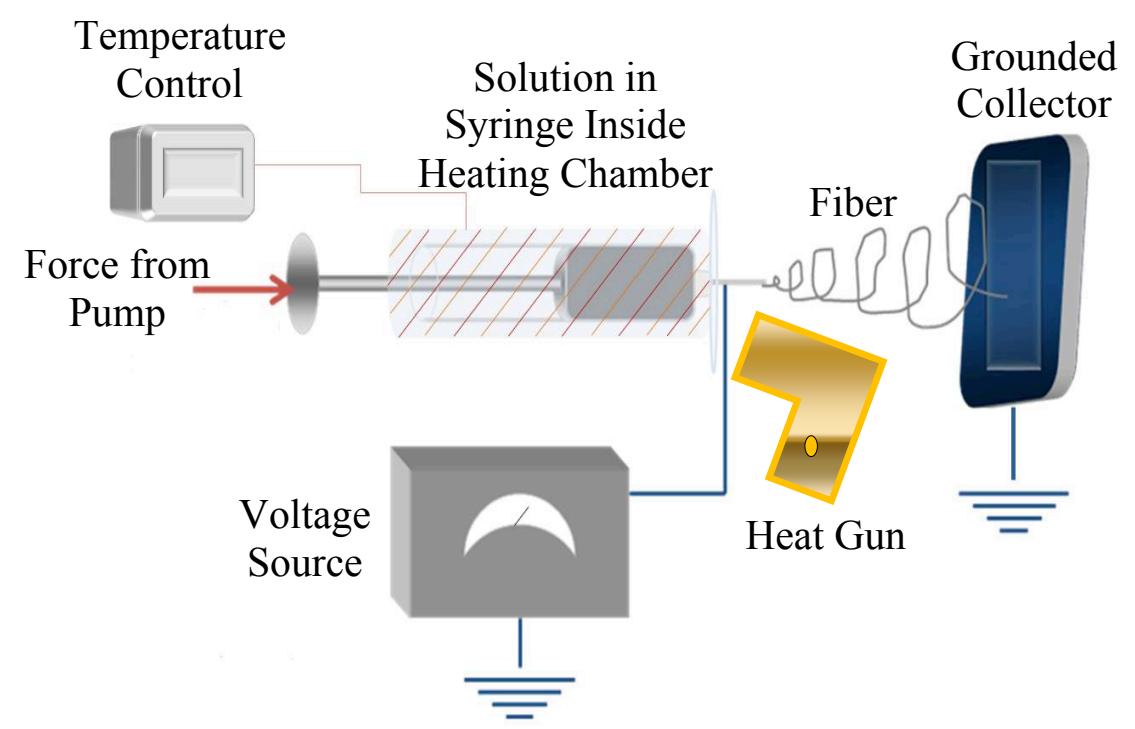

Figure 1. An electrospinning apparatus.

Coaxial electrospinning is a technique implemented to produce nano to micro scaled sheath/core fibers[37-40]. This technique requires two polymer solutions, two syringes, and an electric field as shown in Figure 2.[38] Having two syringes requires the flow rates to be controlled separately.[38] The core and sheath used in this technique requires immiscibility of the two polymer solutions.[39] The coaxial electrospinning technique is very sensitive to the position of 
the core syringe.[41] Therefore the scaling up of this technique is still being researched due to its difficulty of controlling flow rates of both solutions as well as its sensitivity to position of the core syringe. $[38,41]$ Due to these limitations, the research reported here will focus on achieving combined properties of two polymers using one spinning.

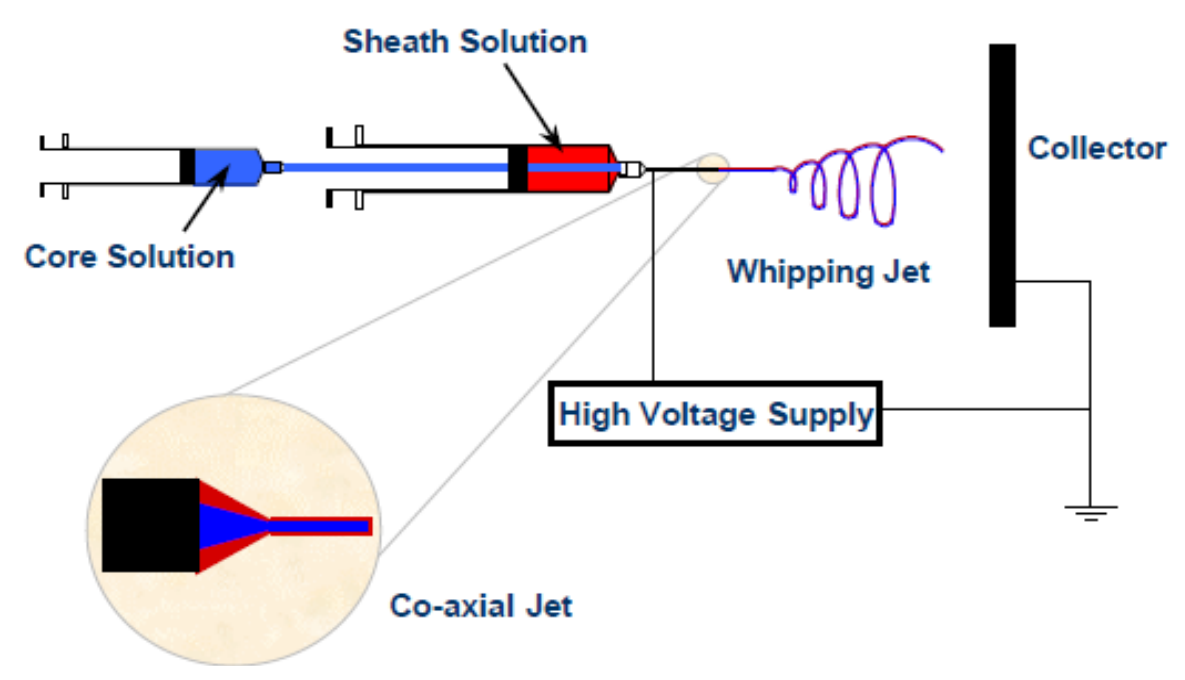

Figure 2. Coaxial electrospinning apparatus. Figure taken directly from [38].

Several different methods employed have been employed for scaling up the electrospinning such as multiplexing to spin numerous jets from multiple needles, and producing multiple jets directly from the surface of a polymer solution without needles; needle-less electrospinning.[42-45] Three main requirements should be considered to scale up the electrospinning process using numerous jets from multiple needles: the type of needles, the number of needles, and the position of the needles relative to one another.[42] These parameters must be considered so that the jets from the multiple needles do not interfere with one another.[42-44] A limitation to this scale-up electrospinning process is that it depends on the electrospun solutions, therefore if the solutions were changed, the three parameters would have to be re-determined for the new solution. [42] When considering multiple jets from a needle-less electrospinning apparatus, electric and magnetic fields are employed. This is a two layer system that drives polymer solutions with a 
lower magnetic field to the outer layer with an applied electric field to create nanofibers. $[42,46$, 47] This technique has demonstrated greater productivity and clogging issues are prevented, which is commonly experienced with the traditional method of electrospinning with a needle. $[42,45]$ It is important to know that these scale-up methods are available; however they are beyond the scope of this research. Because the work reported here uses a single spinning solution, scale-up via any current method should be viable. Polymers with dissimilar polarizabilities and hydrophobicity have been shown to phase separate in the large electrostatic field generated during electrospinning as homogeneously dissolved polymers are electrospun and the solvent is evaporated. [33, 36-39] Simultaneously, thermodynamics favors phase separation in mixtures of dissimilar polymers. A schematic of a phase separation diagram is shown in Figure 3.

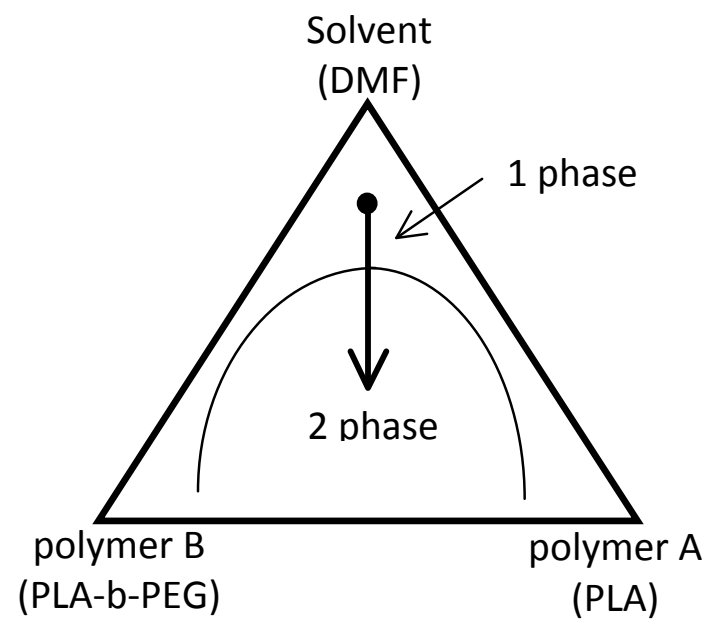

Figure 3. Phase separation of two polymers dissolved in solvent. Drawn after [48].

The combination of PLA and PLA-b-PEG was chosen due to the combined hydrophobic/hydrophilic properties. PLA is hydrophobic, while PEG is hydrophilic.[49] The combination of the PLA and PEG creates a polymer fiber with a greater hydrophilic nature than that of just a PLA homopolymer fiber. The chemical structures of the polymers as seen in Figure 
4 can be used to assess their hydrophobic/hydrophilic nature. In general, hydroxyl groups on polymers can either have strong affinity to water or have very little interactions.[50] In the case of PEG, the hydroxyl group provides a more hydrophilic nature compared to PLA. The hydrophilic nature of PEG is due to the ether segments that make it very polar and the ether oxygen atoms that act as hydrogen-accepting sites. [51, 52]

\section{PLA}

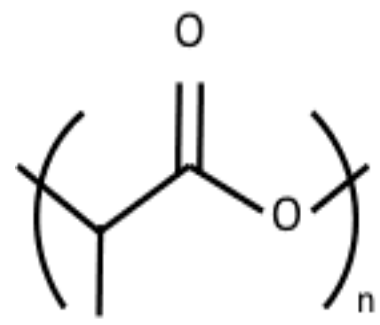

PEG

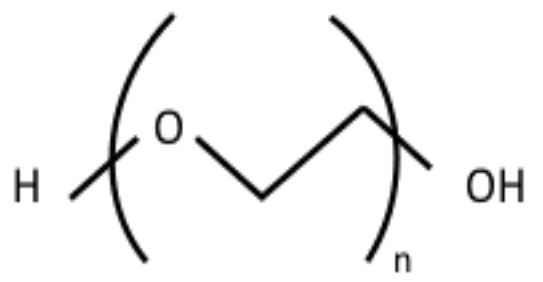

Figure 4. PLA and PEG chemical structures.

The nanofibers formed in this study have an increasing concentration of the hydrophilic polymer, PEG from the center of the fiber to the surface which is to aid in the desired surface properties as shown in Figure 5. By achieving this phase separation, the properties of the PEG can be exploited due to the hydroxyl end groups of PEG that can allow for covalent attachment with other molecules.[53] Therefore this research seeks to use the single step thermodynamically driven phase separation that occurs during electrospinning to create a fiber with a different composition at the surface than at the core. 


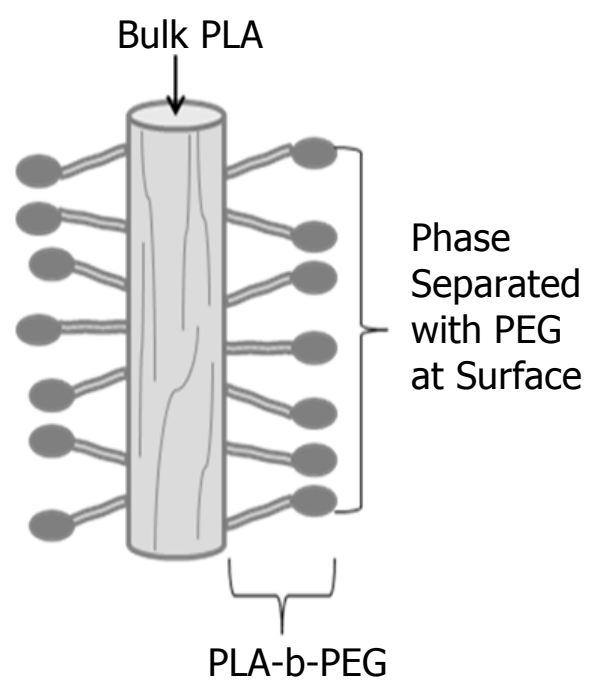

Figure 5. Fiber produced by phase separation during electrospinning. Drawn after[33] .

Thermodynamics generally dictates the structure of polymers because the structure's mode of growth is dependent on phase separation.[54, 55] To achieve the desired polymer structure however, multiple steps are usually taken which can take hours to complete. Typically to arrive at a specific structure, such as the lamellar, the copolymer must be cast into a film, dried at room temperature, dried under vacuum, quenched, and heated.[56] In the case of electrospinning form a dilute solution via a charged elongating jet, the rapid evaporation of the solvent, is thought to result in the desired structure in a matter of milliseconds.

When adding PEG to PLA in the form of a copolymer PLA-b-PEG, PEG block lengths affect a number of properties regarding the electropun fibers. Such properties include the total amount of PEG allowable in the fiber, spinnability, and morphology.[33] By the addition of PEG to PLA the hydrophilic nature of the fiber increases, and it is further assisted by the longer chain length of PEG in the copolymer as shown in previous studies by Hendrick et al. in Figure 6.[33] 


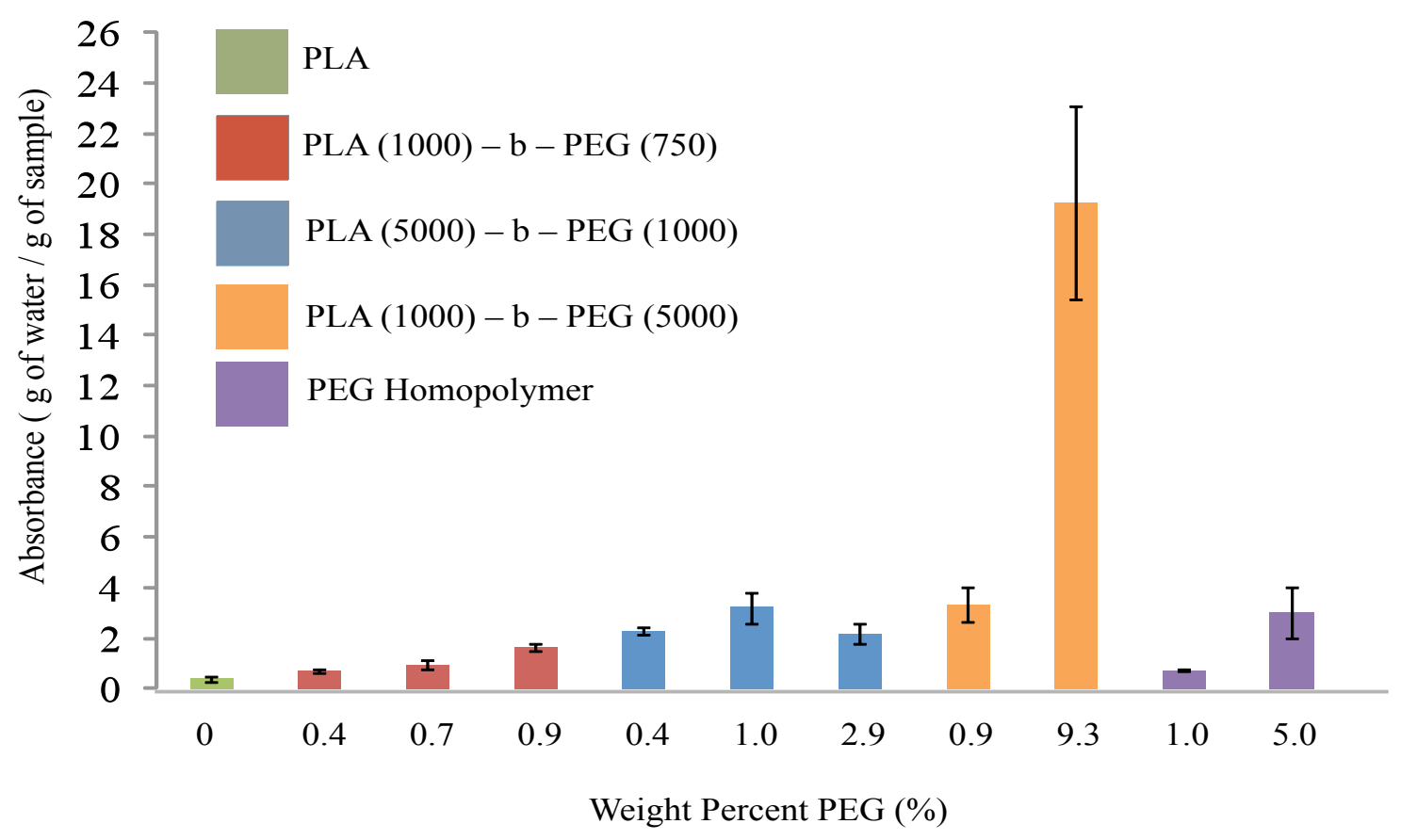

Figure 6. E. Hendrick et al. wettabllity data for PLA, and PLA-b-PEG electrospun fibers. Taken directly from [33].

Four block copolymers were used in combination with homopolymer PLA. Homopolymer PEG(6000) was also spun in combination with homopolymer PLA. It is thought that with larger PEG block lengths with a higher wt $\%$ in solution the solution may fail to electrospin.[33] The smaller PEG block lengths then are expected to allow for more PLA-b-PEG to be used within the solutions. Solutions with higher PEG block lengths that electrospun into nanofibers are expected to have higher water uptake as shown by Hendrick et al.[33] Therefore from the polymeric solutions being made, it is expected that the wettability will increase with increasing PEG block length, and increasing PEG homopolymer.

\section{Materials}

Needle Deflect point 20gx2inches bought from Fisher Scientific Company LLC (Suwanee, GA). Copolymers PLA(1000)-b-PEG(10000), PLA(1000)-b-PEG(5000), PLA(5000)-b-PEG(1000), 
PLA(2200)-b-PEG(5000)-N3 were purchased from Advanced Polymer Materials Inc. (Canada) . Polyethylene Glycol(6000) Powder made by Alfa Aesar was bought from Fisher Scientific Inc (Pittsburg,PA). N,N-Dimethylformamide, Anhydrous, 99.8\% was purchased from SigmaAldrich (St. Louis, MO). PLA 4043D (MW=153,315g/mol, PDI=1.81) were purchased from NatureWorks LLC(Minnetonka, MN).

\section{Methods}

\section{i. Electrospinning}

Electrospinning solutions of $22 \mathrm{wt} \%$ PLA (total PLA wt $\%$ that includes both homopolymer and PLA copolymer in calculation) with varying weight percentages of PLA-b-PEG block copolymer were made. This was done to investigate the effect of the PLA-b-PEG block copolymer on the overall fiber. Before electrospinning the polymeric solutions dissolved homogeneously with heat and placed on a hot plate for at least 1.5 hours. A voltage supply (Gamma high Voltage Research Inc., FL) was used to apply $15 \mathrm{kV}$ to the needle. A grounded collector was located approximately $10 \mathrm{~cm}$ from the needle tip. A $10 \mu \mathrm{L} / \mathrm{min}$ feed rate driven by a programmable PHS Ultra syringe pump (Harvard Apparatus) was applied to the syringe. During electrospinning the syringe temperature was controlled by a shielded heating unit provided by Dr. Daehwan Cho and was pre-heated to $70^{\circ} \mathrm{C} \pm 5^{\circ} \mathrm{C}$. A heat gun (Master Appliances Corp. Racine, WI) was used to keep the needle at approximately $70^{\circ} \mathrm{C} \pm 5^{\circ} \mathrm{C}$. The temperature of the needle was taken at a point approximately $2 / 3$ of the way up from the base of the needle with a digital thermometer (Fisher Scientific Company LLC). For the wettability samples, the electrospun nanofibers were collected onto a copper plate, while all other samples were electrospun onto aluminum foil. Table 1 contains the final calculated fiber contents that were achieved by electrospinning. A 
solution of homopolymer PLA was also tested as a control. All solutions containing PEG and PLA-PEG were made to contain a total of $22 \mathrm{wt} \%$ PLA in solution.

Table 1. Final fiber content using various solutions.

\begin{tabular}{ccccc}
\hline $\begin{array}{c}\text { PLA-PEG block } \\
\text { lengths /PEG } \\
\text { homopolymer }\end{array}$ & $\begin{array}{c}\text { Total PLA in } \\
\text { Final Fiber } \\
\text { (Wt\%) }\end{array}$ & $\begin{array}{c}\text { Total PEG } \\
\text { in Final } \\
\text { Fiber (Wt\%) }\end{array}$ & $\begin{array}{c}\text { PLA } \\
\text { Homopolymer in } \\
\text { Final Fiber (Wt\%) }\end{array}$ & $\begin{array}{c}\text { Block Co-polymer } \\
\text { in Final Fiber } \\
\text { (Wt\%) }\end{array}$ \\
\hline PLA(5000)-b- & 96 & 4 & 76 & 24 \\
PEG (1000) & 95 & 5 & 72 & 28 \\
PLA(1000)-b- & 94 & 6 & 63 & 37 \\
PEG(5000) & 95 & 5 & 94 & 12 \\
& 90 & 10 & 88 & 14 \\
& 86 & 12 & 86 & 17 \\
PLA (1000)-b- & 84 & 14 & 83 & 6 \\
PEG(10000) & 95 & 16 & 81 & 11 \\
& 90 & 5 & 94 & 13 \\
& 88 & 10 & 99 & 17 \\
PLA(2200)-b- & 86 & 12 & 87 & 17 \\
PEG(5000)-N3 & 84 & 16 & 85 & - \\
PEG(6000) & 95 & 12 & 83 & - \\
(Homopolymer) & 90 & 10 & 83 & - \\
& 88 & 12 & & -- \\
\hline
\end{tabular}

\section{ii. Scanning Electron Microscopy (SEM)}

SEM imaging was used to verify that the PLA/PLA-b-PEG nanofibers have the same morphology as the PLA fibers. The samples were sputter coated with gold-palladium, and imaged on a LEICA 440 SEM using a $10 \mathrm{kV}$ accelerating voltage. The average diameters of the fibers were determined by evaluating the SEM images using Image ${ }^{\mathrm{TM}}$ software. For each different fiber spun, twenty-five measurements from two separate images were taken, totaling fifty measurements per sample. 


\section{iii. Differential Scanning Calorimetry (DSC)}

DSC Q2000 was employed to determine the effects of PEG on the overall fiber properties. The glass transition, melting, and crystallization temperatures were characterized with this technique. The PLA(1000)-b-PEG(10000) was run from $32^{\circ} \mathrm{C}$ to $190^{\circ} \mathrm{Cat}$ an increase of $5^{\circ} \mathrm{C} / \mathrm{min}$. After seeing some of the results from the PLA(1000)-b-PEG(10000) the starting temperature was changed to $5^{\circ} \mathrm{C}$. This was done to better see the glass transition temperature. The rate of temperature increase and ending temperatures were kept the same. A heat-cool-heat method was used for 10wt\% PEG from PEG(6000), PLA(1000)-PEG(5000), and PLA(1000)-PEG(10000). These tests were done on leftover samples that were previously made, so repeats were not performed for the heat-cool-heat method. The samples were heated from $5^{\circ} \mathrm{C}$ to $180^{\circ} \mathrm{C}$ at a rate of $5^{\circ} \mathrm{C} / \mathrm{min}$, cooled to $5^{\circ} \mathrm{C}$ at a rate of $2^{\circ} \mathrm{C} / \mathrm{min}$, and re-heated at a rate of $5^{\circ} \mathrm{C} / \mathrm{min}$.

iv. X-Ray Photoelectron Spectroscopy (XPS)

XPS was be used to analyze PLA(2200)-b-PEG(5000) with nitrogen attached to the end of the PEG. The amount of PEG migrating to the surface of the fibers was thought to be more quantifiable due to the addition of nitrogen. This data was collected by Jon Shu at the Cornell Center for Materials Research.

\section{v. Fourier transform infrared spectroscopy (FTIR)}

FTIR analysis was performed to determine if -N3 was present in the PLA(2200)-b-PEG(5000)N3 powder and12wt\% PEG from PLA(2200)-b-PEG(5000)-N3 electrospun samples. 0wt\%PEG, 12wt\%PEG from PLA(1000)-b-PEG(5000), and 12wt\% PEG from PLA(1000)-b-PEG(10000) 
were also tested for comparison. The number of scans was set to 128 and a range of 3300-1500 wavenumber was used.

vi. Time-of-flight Secondary Ion Mass Spectrometry (ToF-SIMS)

Tof-SIMS was used to further verify and quantify the amount of PEG migrating to the surface of the nanofibers. The analysis was done by Sachin Attavar at EAGLabs. A gallium liquid metal ion gun (LMIG) primary ion source was used to gather the data. The instrument was operated in an ion microprobe mode in which the bunched, pulsed primary ion beam was rastered across the sample's surface. Three positive ion spectra were acquired from each sample in order to confirm the reproducibility of the data. Using Region of Interest feature, data was acquired from a smaller region of raw data. The data were collected within the static limit thus molecular fragments are indicative of species existing on the surfaces prior to analysis. The sampling depth was approximately 1-3 monolayers.

vii. Swell Test

Electrospun samples of $0 \mathrm{wt} \% \mathrm{PEG}$ and of $10 \mathrm{wt} \%$ PEG from PEG(6000),PLA(1000)-bPEG(5000), PLA(1000)-b-PEG(1000) were left in a desiccator for 6-7 days prior to being cut into $1 \mathrm{~cm} x 1 \mathrm{~cm}$ squares. The samples were individually placed in DI water, pushed down into the water with tweezers, and then allowed to float to the top. Each sample was kept in the water for ten minutes. The non-woven samples were then re-measured with a ruler, and later SEM images were taken to determine the effect of water on the fibers. 


\section{viii. Wettability in Water}

Nanofibers were electrospun onto copper plates as wettability samples to investigate their water wicking rate. Each sample was cut into $3 \mathrm{~cm} \mathrm{x} 1 / 2 \mathrm{~cm}$ fabrics. The samples were weighed and then a fishhook was put through the nonwoven fabric to ensure the fabric went through the water meniscus. Wettability testing was done using the KSV Sigma 701 in DI water. The experimental set up is shown in Figure 7. Each sample was run for a ten minute time interval.

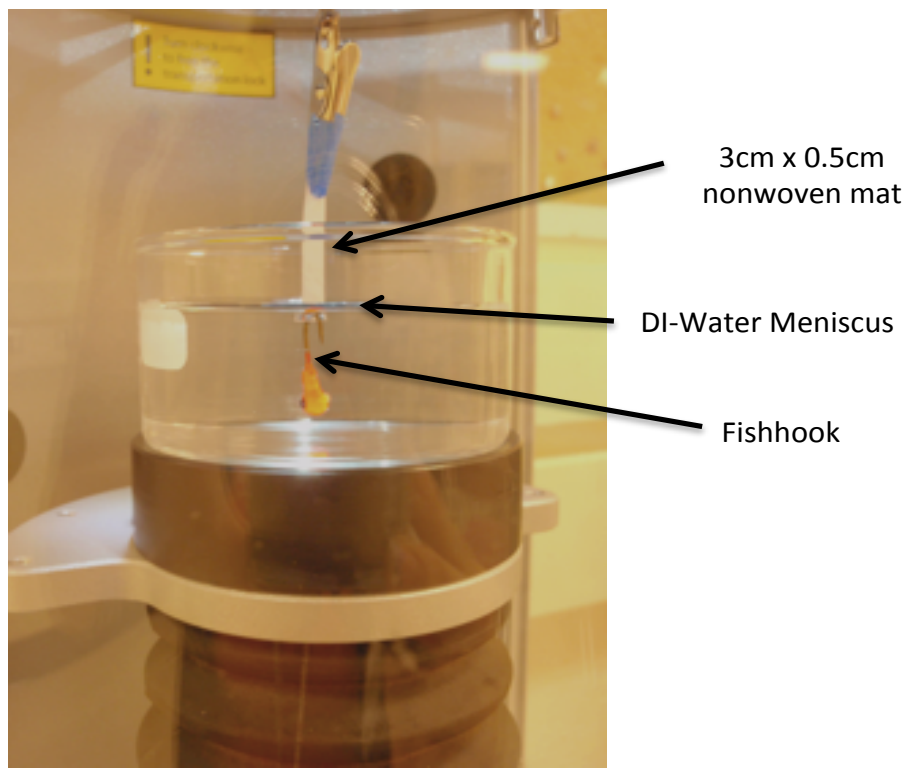

Figure 7. Wettability testing setup.

\section{Statistical Analysis}

At least five samples of each composition were tested for wettability. Two different electrospun samples were tested for DSC analysis to confirm that the trend was reproducible (this was true for all samples except the $16 \mathrm{wt} \% \mathrm{PEG}$ from PLA(1000)-b-PEG(10000) due to shortage of sample). T-Tests were performed for SEM diameters and wettability results. 


\section{Results \& Discussion}

\section{i. $\quad S E M \&$ ImageJ $^{\mathrm{TM}}$}

SEM images were taken to compare 0, 4, 5, and 6wt\% PEG from PLA (5000)-b-PEG(1000).

The images are shown in Figure 8 A-D. The fiber with no PEG has a smooth morphology

with no beading; however it has the largest fiber diameter. At $6 \mathrm{wt} \%$ PEG beading is

observed. As the PEG is increased the fibers become smaller in diameter, however the morphology begins to change resulting in flat and beady fibers.
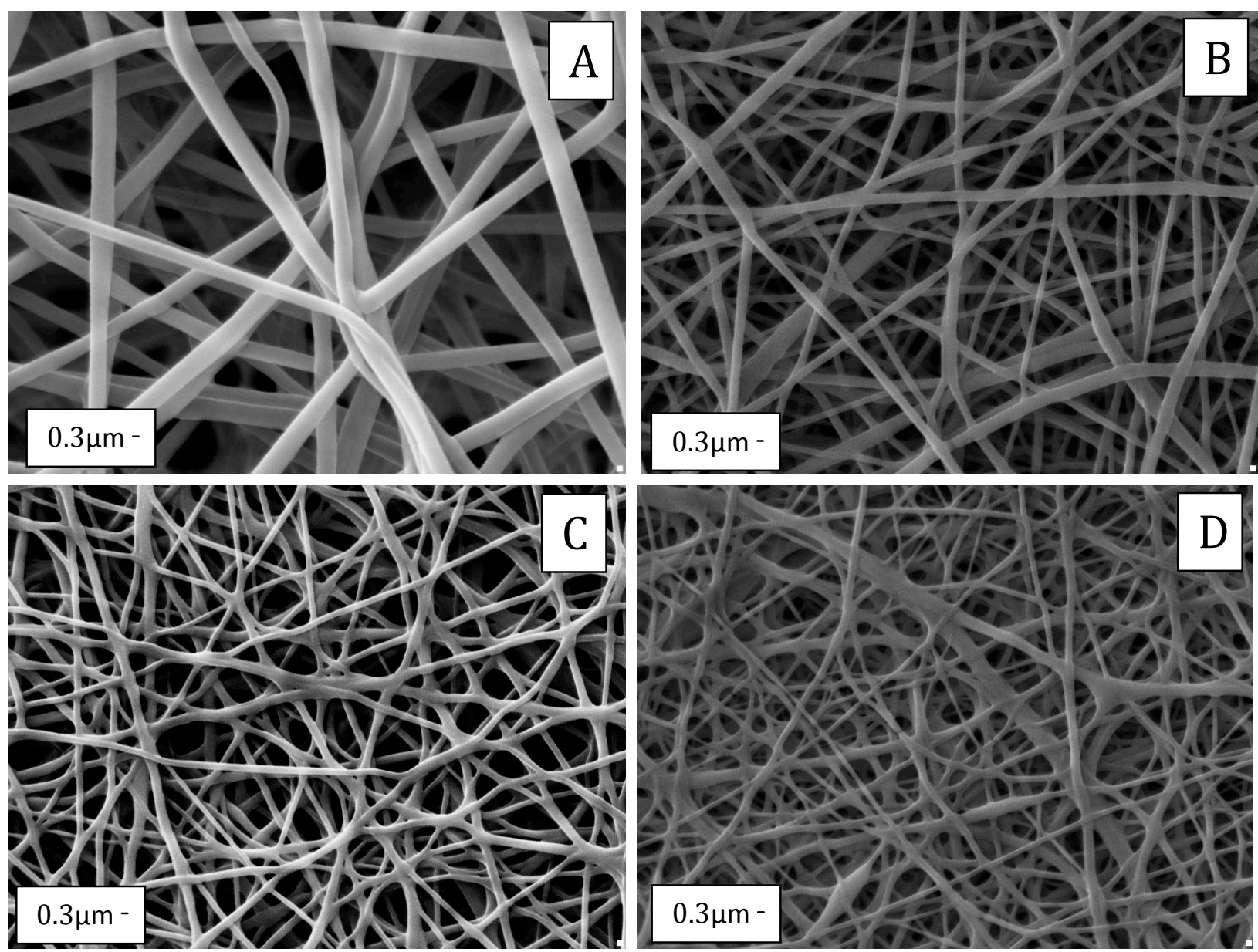

Figure 8. SEM images of : A) $100 \mathrm{wt} \%$ PLA fiber. B) 4wt $\%$ PEG from PLA(5000)-b-PEG(1000) fiber. C) $5 \mathrm{wt} \%$ PEG from PLA(5000)-b-PEG(1000) fiber. D) $6 \mathrm{wt} \%$ PEG from PLA(5000)-bPEG(1000) fiber. 
Using Image $\mathrm{J}$, the average diameter was determined. At 4, 5, and $6 \mathrm{wt} \% \mathrm{PEG}$, the diameter decreased significantly from the $0 \mathrm{wt} \% \mathrm{PEG}$. This can be attributed to the addition of PEG as well as to the overall PLA content in solution being kept at $22 \mathrm{wt} \%$. At $22 \mathrm{wt} \% \mathrm{PLA}$ in solution, copolymer PLA(5000)-b-PEG(1000) results in a visibly very low viscosity solution.

SEM images were taken to compare $0,5,10,12$, and $16 \mathrm{wt} \%$ PEG from PEG(6000), PLA (1000)-b-PEG(5000), and PLA(1000)-b-PEG(10000). SEM images gathered for PEG(6000), PLA(1000)-b-PEG(5000), and PLA(1000)-b-PEG(10000) are shown in shown in Figures 9 A-F, $10 \mathrm{~A}-\mathrm{F}$, and 11A-F respectively. 

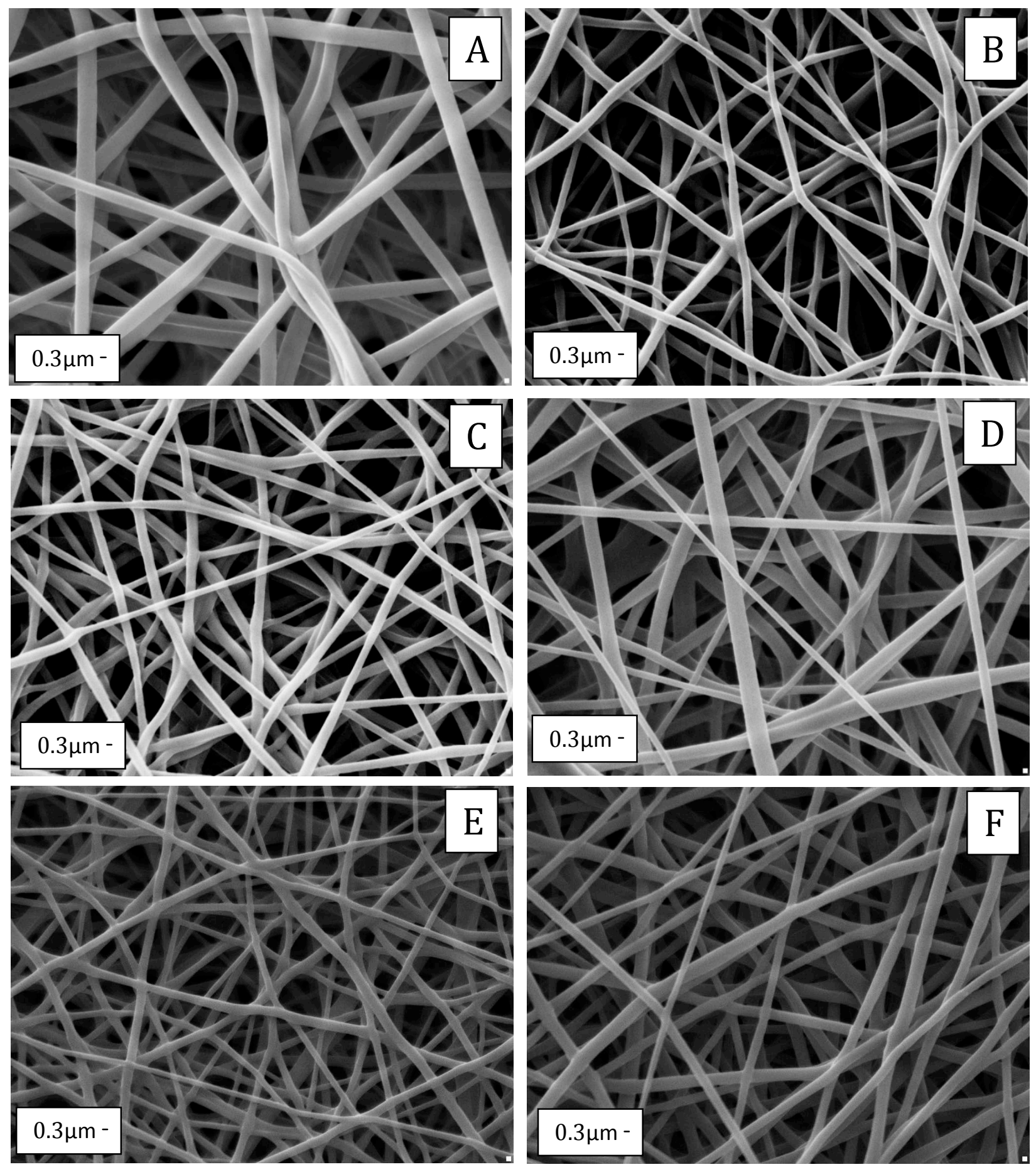

Figure 9. SEM images of : A) $100 \mathrm{wt} \%$ PLA fiber. B) $5 \mathrm{wt} \%$ PEG fiber. C) $10 \mathrm{wt} \%$ PEG fiber. D) $12 \mathrm{wt} \%$ PEG fiber. E) $14 \mathrm{wt} \%$ PEG fiber. F) $16 \mathrm{wt} \%$ PEG fiber. 

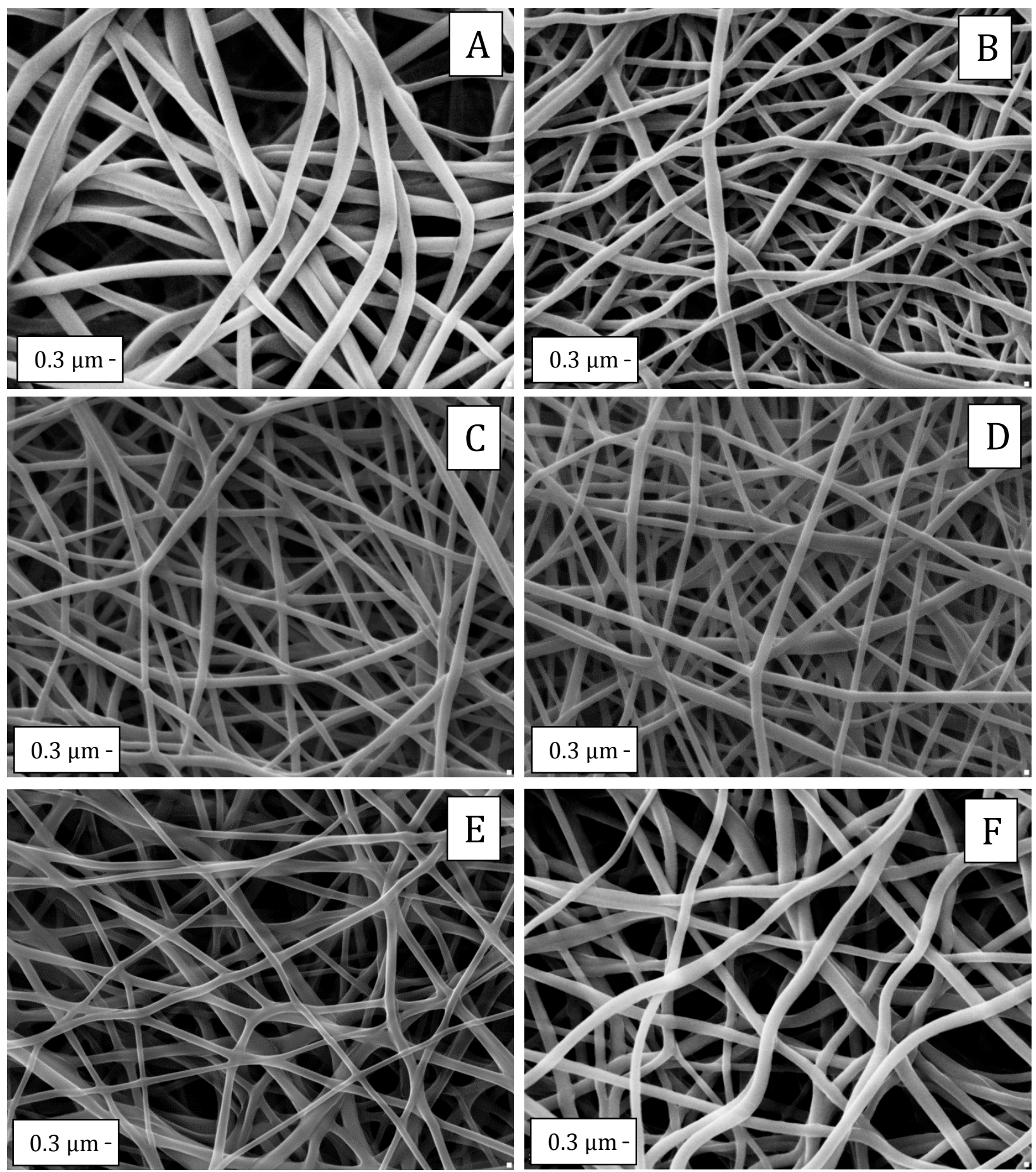

Figure 10. SEM images of : A) 100wt\%PLA fiber. B) $5 \mathrm{wt} \%$ PEG from PLA(1000)-b-PEG(5000) fiber. C) $10 \mathrm{wt} \%$ PEG from PLA(1000)-b-PEG(5000) fiber. D) $12 \mathrm{wt} \%$ PEG from PLA(1000)-bPEG(5000) fiber. E) 14wt $\%$ PEG from PLA(1000)-b-PEG(5000) fiber. F) $16 w t \%$ PEG from PLA(1000)-b-PEG(5000) fiber. 

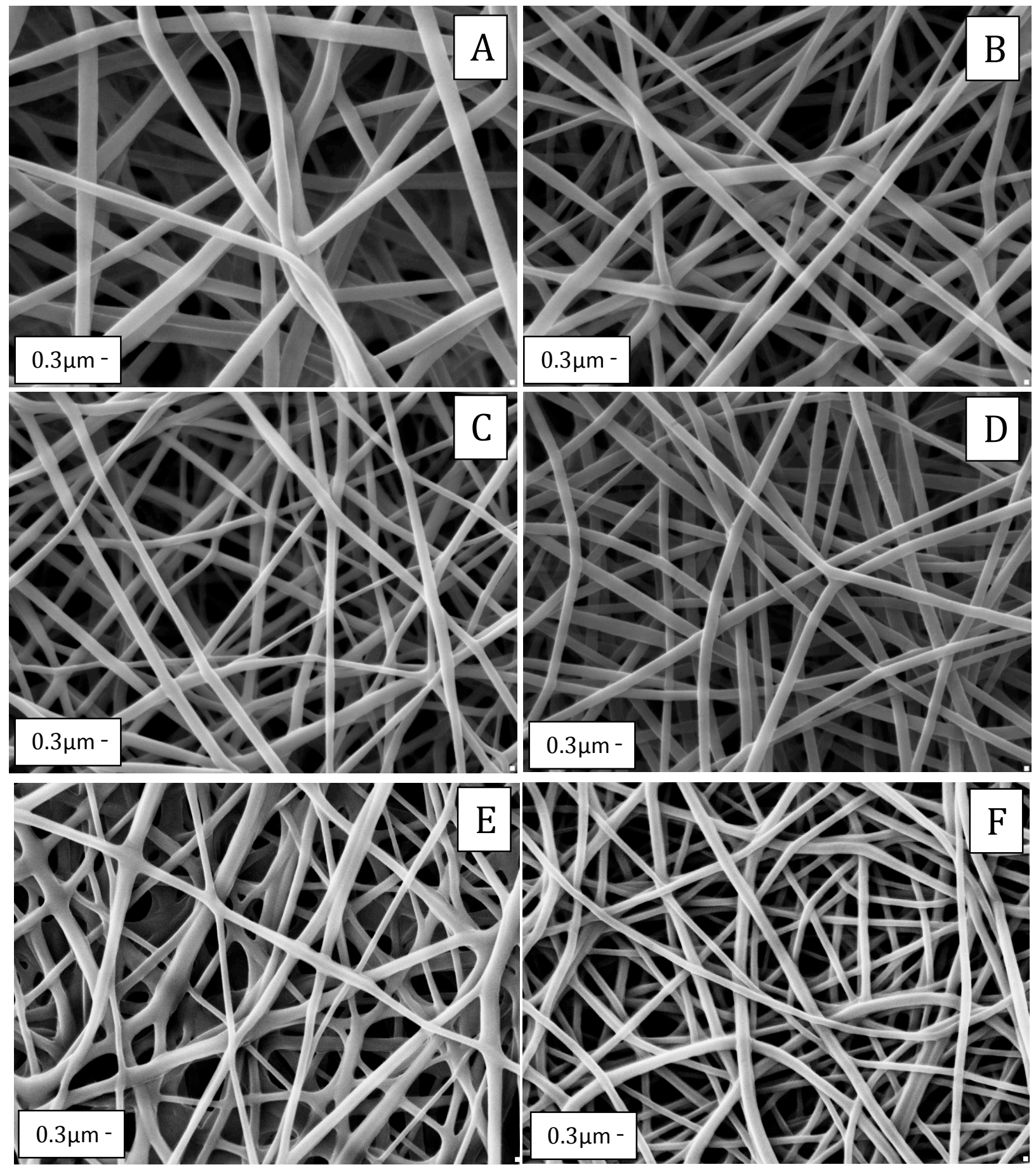

Figure 11. SEM images of : A) $100 \mathrm{wt} \%$ PLA fiber. B) $5 \mathrm{wt} \%$ PEG from PLA(1000)-b-PEG(10000) fiber. C) $10 \mathrm{wt} \%$ PEG from PLA(1000)-b-PEG(10000) fiber. D) $12 \mathrm{wt} \%$ PEG from PLA(1000)-bPEG(10000) fiber. E) $14 w t \%$ PEG from PLA(1000)-b-PEG(10000) fiber. F) $16 w t \%$ PEG from PLA(1000)-b-PEG(10000) fiber.

Again, the fiber with no PEG has a smooth morphology with no beading; however it has the largest fiber diameter. As the PEG is increased, for all copolymers, the fibers become 
significantly smaller in diameter. Decreasing viscosity, decreasing polymer concentration in the spinning solution, and decreasing surface tension of the spinning solution have all been associated with a decrease in fiber diameter.[3, 57] PLA(1000)-b-PEG(10000) however decreases the least in fiber diameter at all weight percents and does not show the same increase at $16 \mathrm{wt} \%$ that PEG(6000) and PLA(1000)-b-PEG(5000) exhibit. In melts of PLA and PEG, PEG was deemed a plasticizer that when added to PLA, lowered the melt viscosity by increasing the free volume.[58] Longer PEG molecular lengths reduce the plasticizing affect of PEG on PLA in melts. [58] Therefore, PLA(1000)-b-PEG(10000) fibers remain large at all weight percents PEG due to its long chains which result in a higher viscosity solution. At $16 \mathrm{wt} \%$ PEG the fiber diameter increased for PEG(6000) and PLA(1000)-b-PEG(5000) due to an increase in viscosity of the polymer solution, and high wt $\%$. For all PEG additions to PLA, the $16 \mathrm{wt} \%$ solution solidified more quickly when taken off the hotplate relative to lower wt\% PEG solutions. A comparison of the average diameters determined from Image JTM for PEG(6000), PLA(5000)-bPEG(1000), PLA(1000)-b-PEG(5000), and PLA(1000)-b-PEG(10000) are shown in Figure 12.

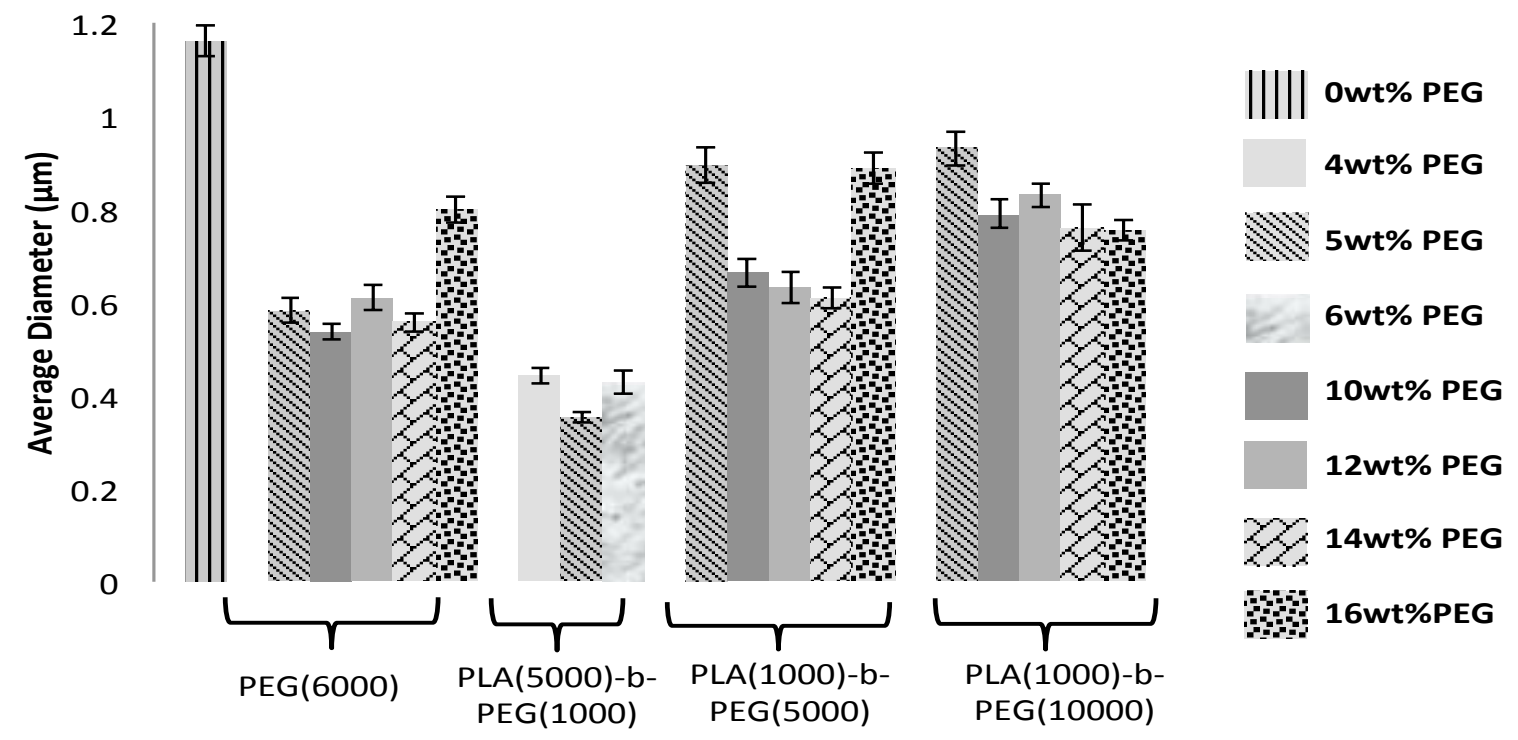

Figure 12. Comparison of average diameters. 
PLA(5000)-b-PEG(1000) was found to have the lowest PEG loading, only being able to be elecrospun with no beads at $5 \mathrm{wt} \%$ PEG. Therefore, proceeding comparisons where greater than 5wt\% PEG was used, PLA(5000)-b-PEG(1000) will be neglected. With 12, 14, and 16wt\% PEG from PLA(1000)-b-PEG(10000) in the final fiber, SEM images demonstrate that although uniform fibers were formed, other areas within the mat contained non-uniform fibers as shown in Figure 13.
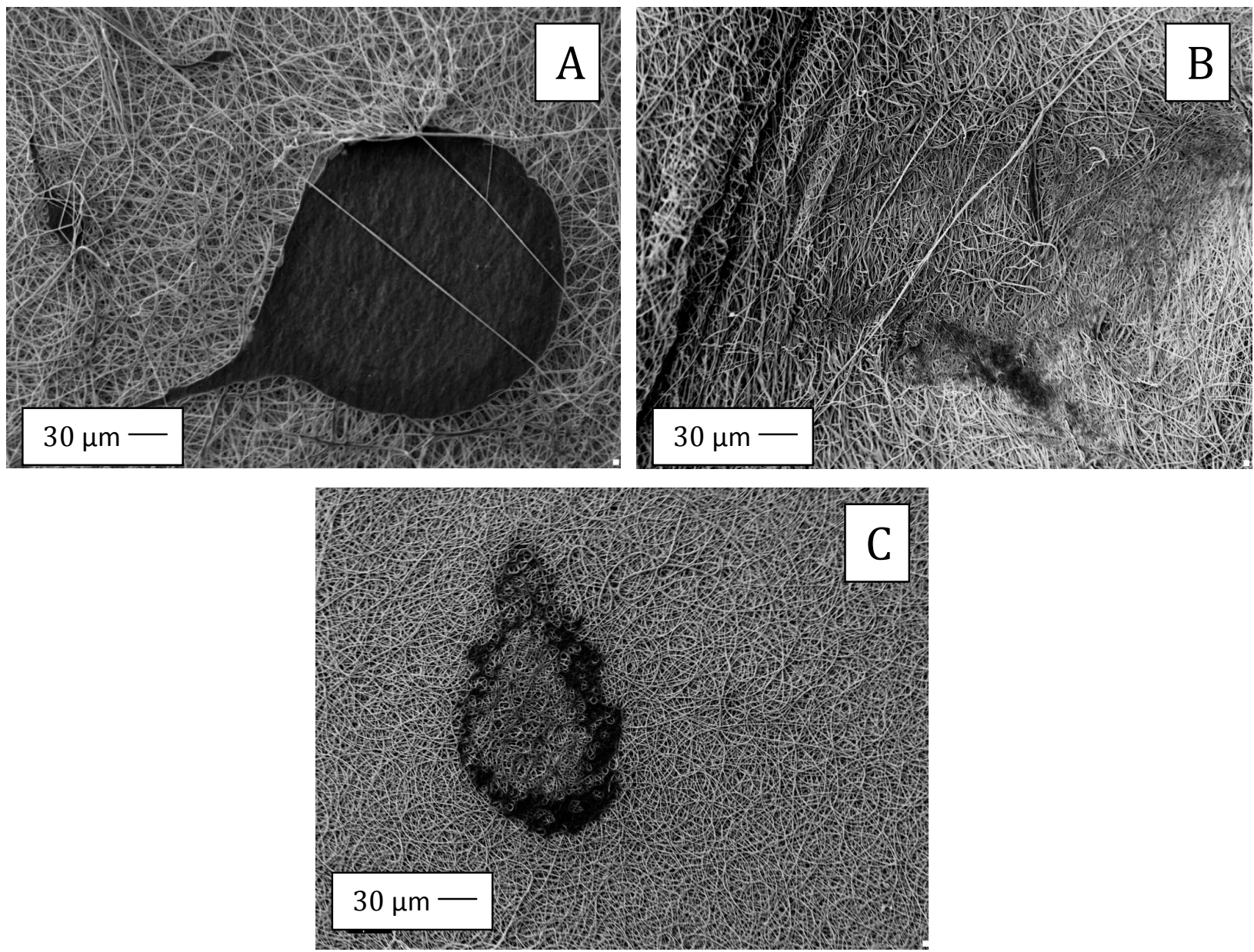

Figure 13. SEM PEG from PLA(1000)-b-PEG(10000) where it is seen that in some areas there is fiber non-uniformity. (A) SEM image of $12 \mathrm{wt} \%$. (B) SEM image of $14 \mathrm{wt} \%$. (C) SEM image of $16 \mathrm{wt} \%$ 


\section{ii. DSC thermal analysis}

The Plasticizing effect of PEG is observed at all additions of PEG, lowering the Tg compared to 0wt\%PEG fibers as shown in Figure 14. With the addition of PLA-b-PEG or PEG to the bulk PLA, there is also a decrease in the cold crystallization temperatures. These shifts to lower glass transition and cold crystallization temperatures indicate that PEG is aiding in the ability of PLA to crystallize.[59] The decrease in both Tc and Tg with the addition of PEG to PLA has been previously documented in films and blends.[59-63]

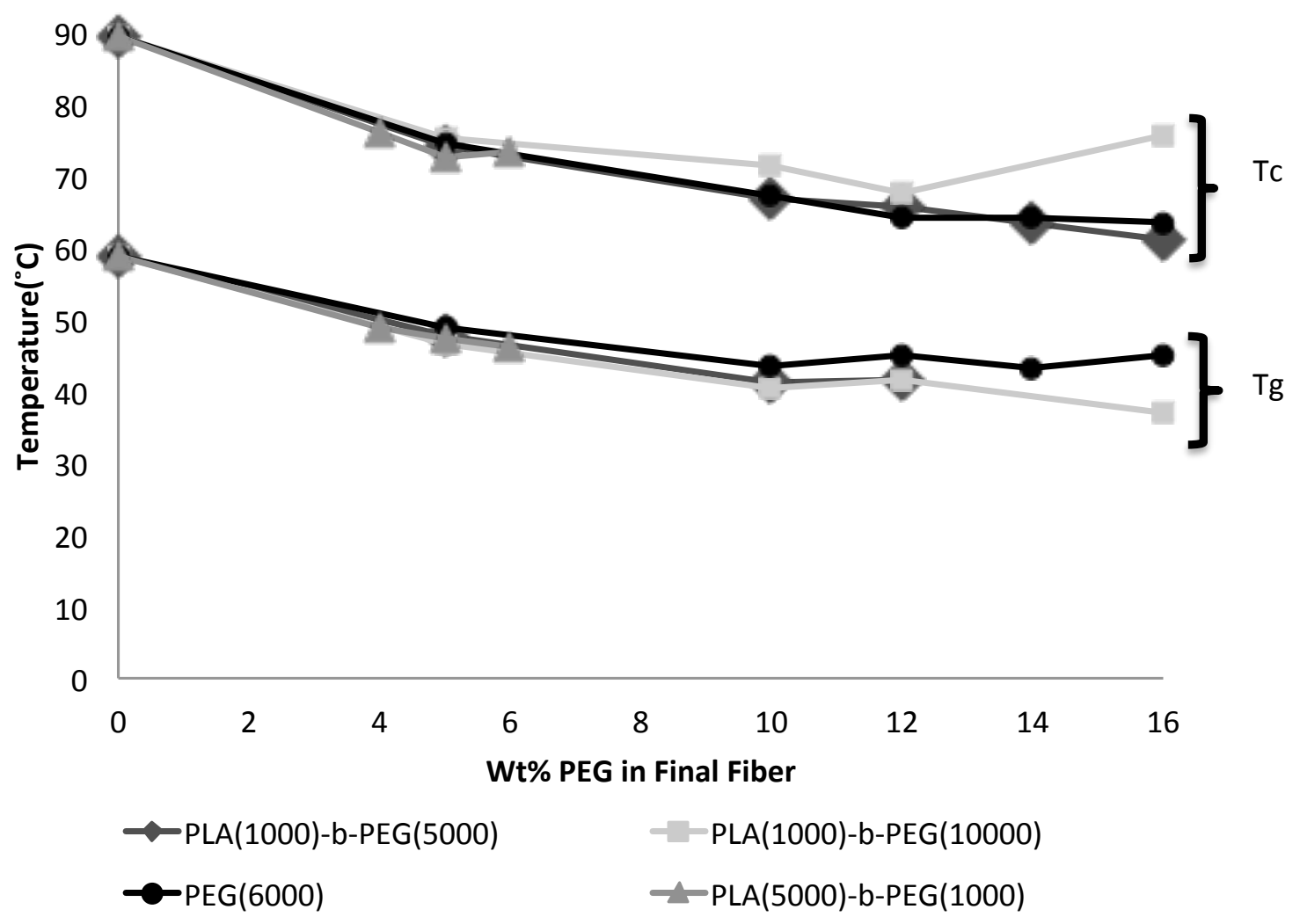

Figure 14. Tc and Tg data trends with increaeing PEG content.

DSC thermographs of PEG(6000), PLA(5000)-PEG(1000), PLA(1000)-b-PEG(5000), and PLA(1000)-b-PEG(10000) all had similar melting peaks of the PLA ranging from $152-154^{\circ} \mathrm{C}$ as 
shown in Figure 15A. The melting temperature of PEG was present for all loadings of PEG(6000), whereas for PLA(1000)-b-PEG(5000) and PLA(1000)-b-PEG(10000) melting peaks for PEG did not become consistent until 12wt\% PEG as shown in Figure 15B.. For one sample of PLA(1000)-b-PEG(5000) at 10wt\%PEG loading, a melting temperature was observed for PEG, indicating that $10 \mathrm{wt} \%$ is the onset of phase separation. No PEG melting point was observed for any wt\% PEG from PLA(5000)-b-PEG(1000). PLA/PEG compression and injection molding blends were investigated by K. Sungsanit et al. It was found that PLA/PEG blends exhibited phase separation after $10 \mathrm{wt} \% \mathrm{PEG}$, attributed to the observation of the PEG melting point in DSC scans.[61]

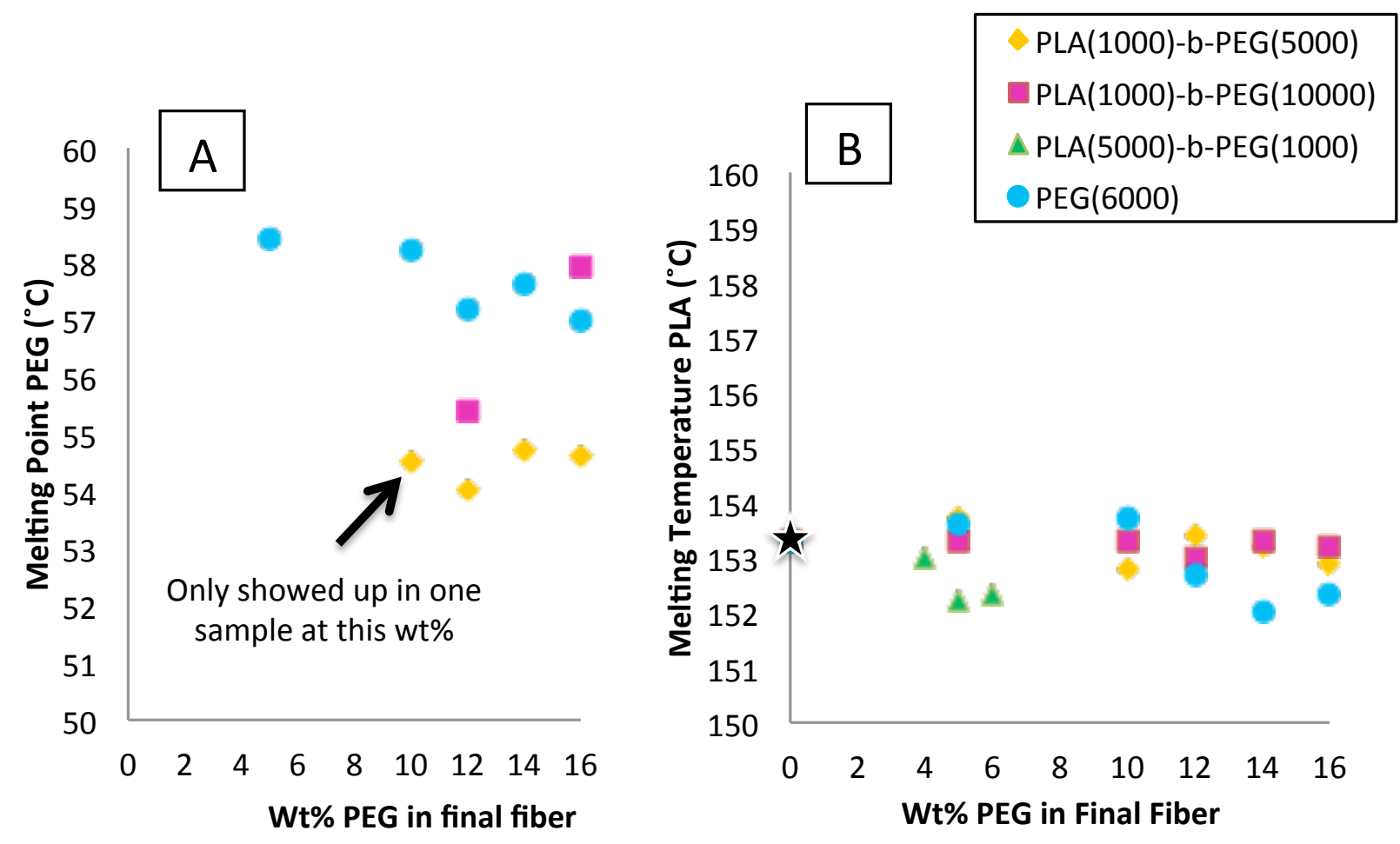

Figure 15. (A) Melting temperatures observed for PEG in various electrospun fibers. (B) Melting temperatures observed for PLA for various electrospun fibers fibers. 
DSC heat-cool-heat thermographs were taken for $0 \mathrm{wt} \%$ PEG fibers and $12 \mathrm{wt} \% \mathrm{PEG}$ from PEG(6000), PLA(1000)-b-PEG(5000), and PLA(1000)-b-PEG(10000) fibers. The heat and cool scans are shown in Figure 16A-B, a factor was added to make graphs legible. When fibers containing copolymer PLA-b-PEG or homopolymer PEG experience the first heat in the DSC, the Tm of PEG is present. The Tm of PEG however is no longer visible upon reheating. This confirms the process of electrospinng is the cause of phase separation of the PLA/ PLA-b-PEG and PLA/PEG fibers.

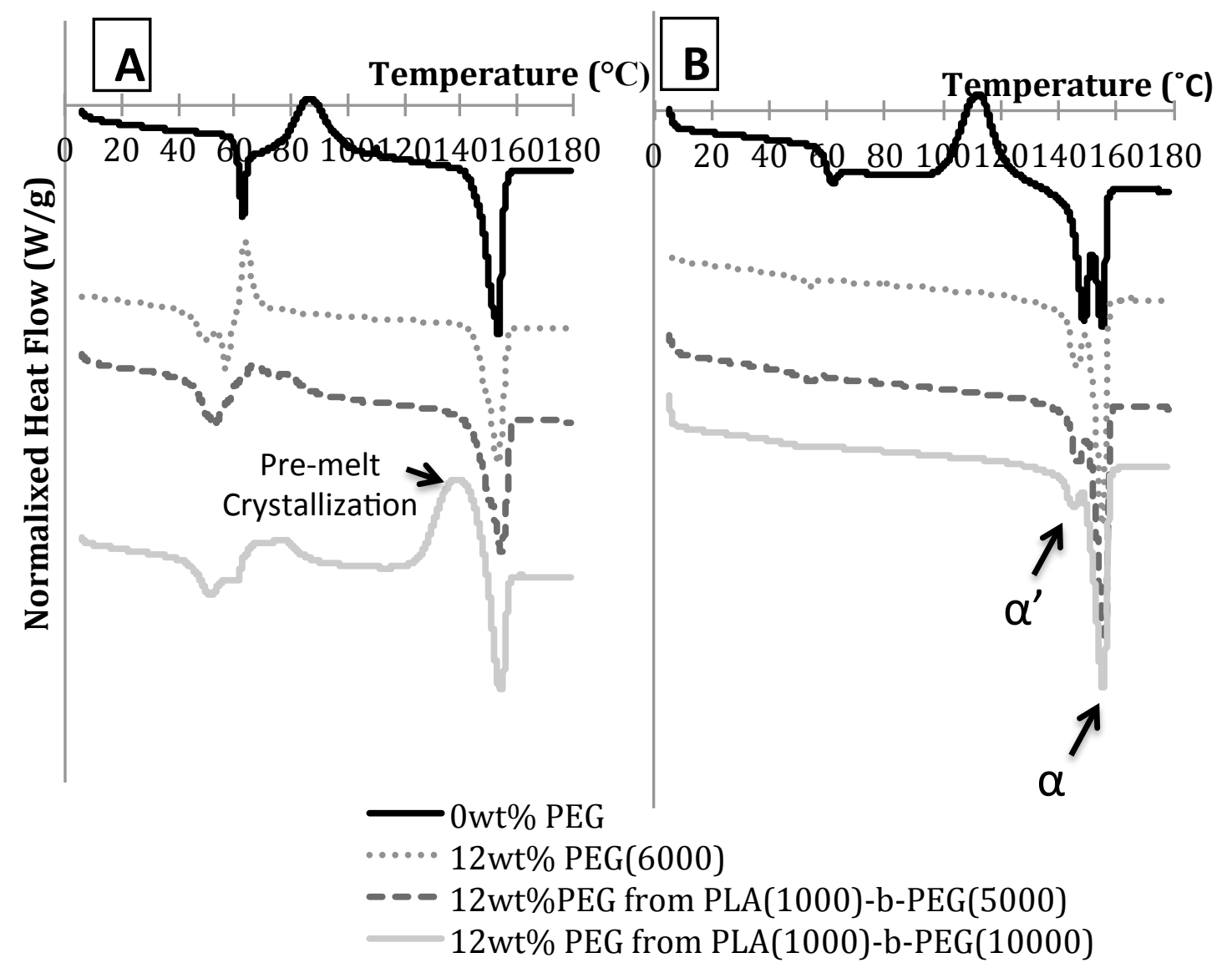

Figure 16. (A) DSC $1^{\text {st }}$ heating scan. (B) DSC scan after the fibers have been cooled and reheated $\left(2^{\text {nd }}\right.$ heating). The DSC results have had a factor added for clarity of graphs. 
The fibers containing PLA-b-PEG or PEG all showed crystallization during the cooling process, while the control homopolymer PLA fibers did not show any crystallization upon cooling. During the re-heating of the fibers the cold crystallization peak is no longer present for fibers containing PLA-b-PEG, or PEG, and example of this is shown in Figure 17. Conversely, the PLA fibers show a shift to higher cold crystallization temperatures. During the re-heating there are two distinct melting peaks for PLA that are representative of the two crystal forms, $\alpha^{\prime}$ and a.[64, 65]

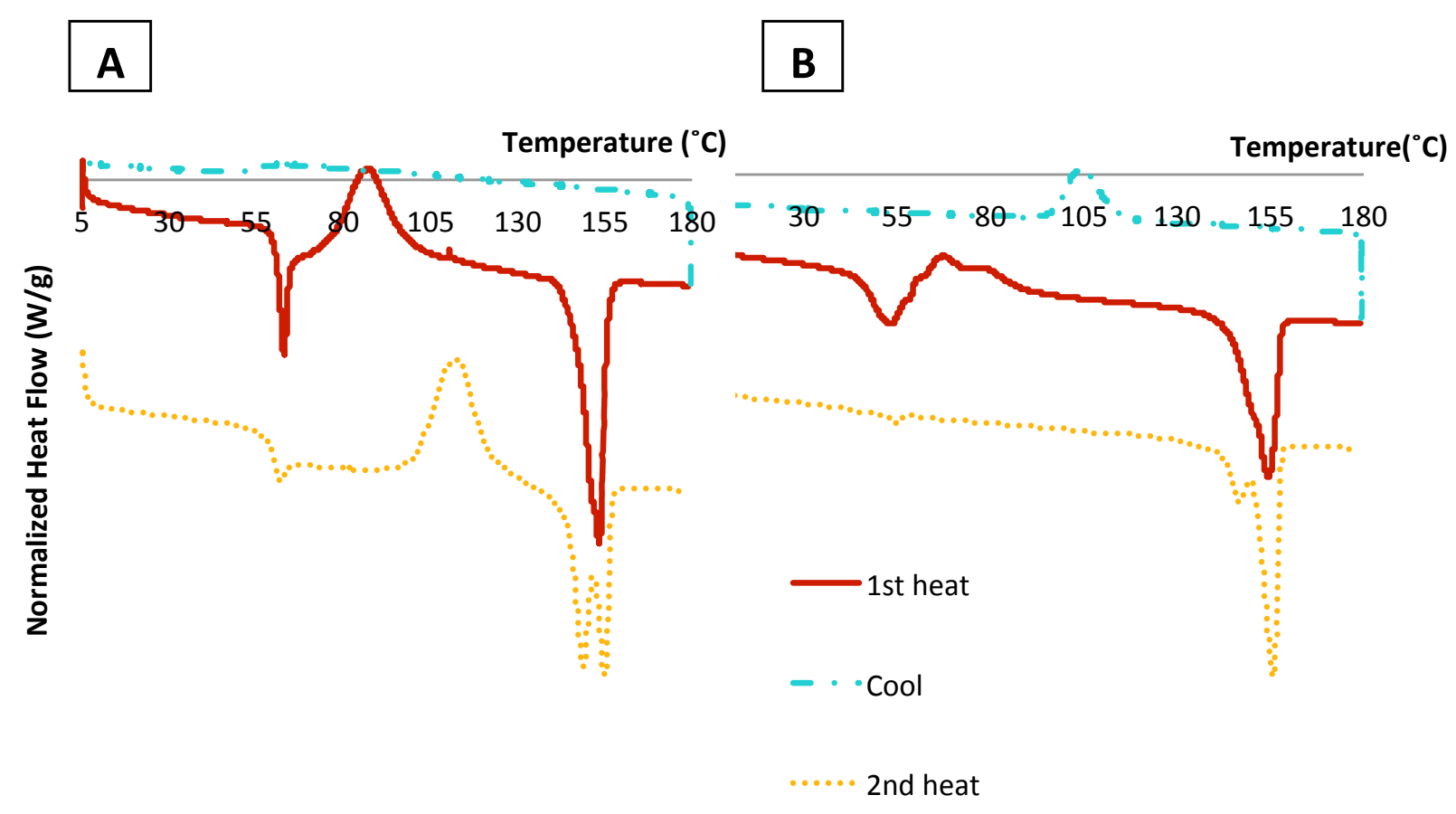

Figure 17. Heat-cool-heat DSC data for (A) $0 \mathrm{wt} \% \mathrm{PEG}$ and (B) $12 \mathrm{wt} \% \mathrm{PEG}$ from PLA(1000)b-PEG(5000).

iii. XPS \& FTIR

The functional groups on $12 \mathrm{wt} \%$ PEG from PLA(2200)-b-PEG(5000)-N3 were observed using XPS analysis in attempt to quantify the amount of PEG migrating to the fiber surface. Unfortunately the XPS results shown in Figure 18 show no difference between the control PLA fibers and the PLA(2200)-b-PEG(5000)-N3. 

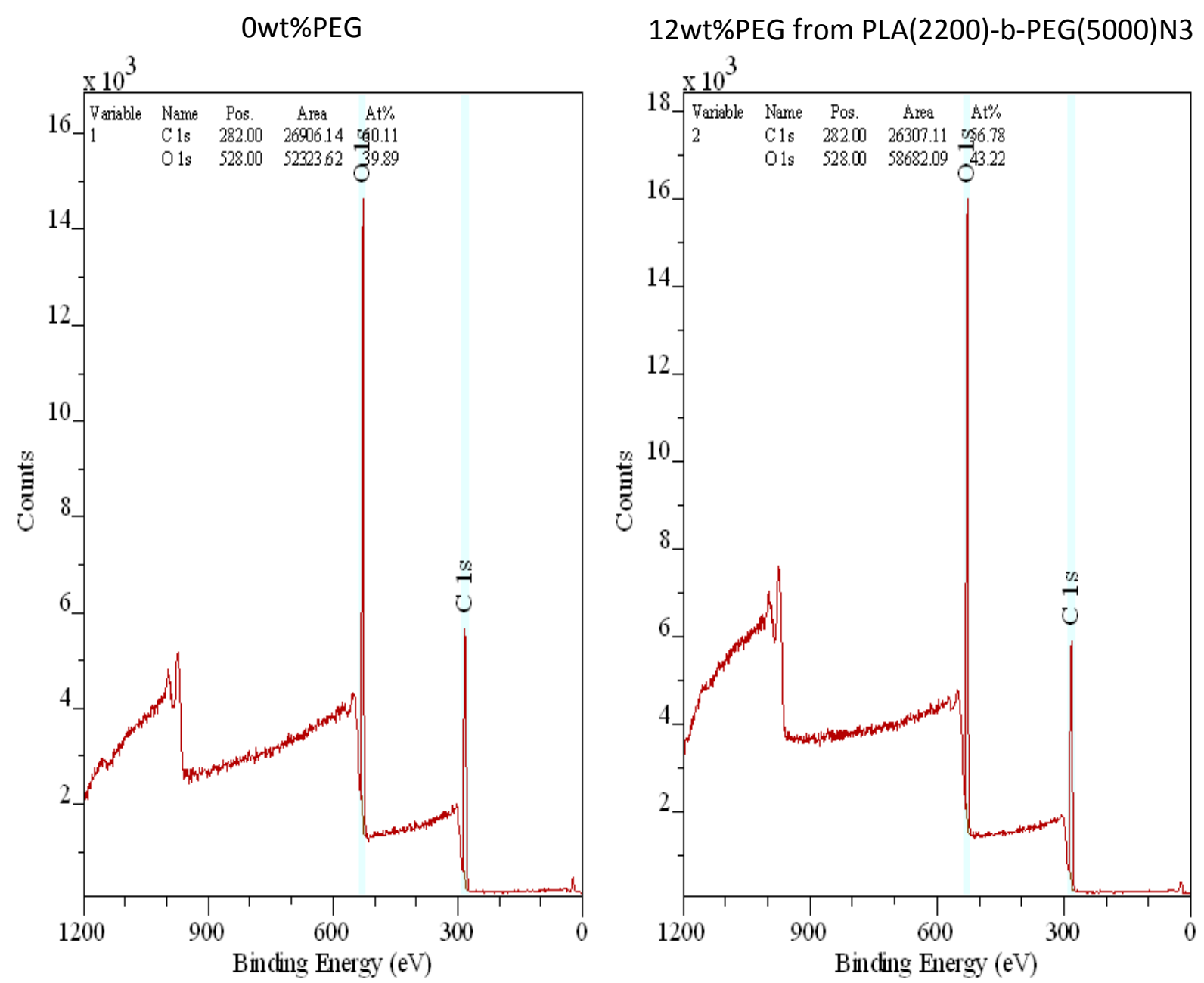

Figure 18. XPS data for $0 w t \%$ PEG fibers and $12 w t \%$ PEG from PLA(2200)-b-PEG(5000) -N3 fibers.

To ensure the polymers received had nitrogen in it, FTIR analysis was done. The two major peaks observed were the $\mathrm{C}=\mathrm{O}$ vibrations at approximately $1750 \mathrm{~cm}^{-1}$ and $\mathrm{C}-\mathrm{H}$ vibrations at approximately $2850 \mathrm{~cm}^{-1}$. The $\mathrm{C}-\mathrm{H}$ vibrations were greater in the powder sample than in the electrospun samples. There were no significant differences between samples, and the $-\mathrm{N} 3$ peak was not present as it should have been located at $2075 \mathrm{~cm}^{-1}$.[66] It is thought that the polymer may have been old, thus a degradation of the -N3 peak may have occurred, or that there was potentially no -N3 ever added into the copolymer. FTIR results are shown in Figure 19. 


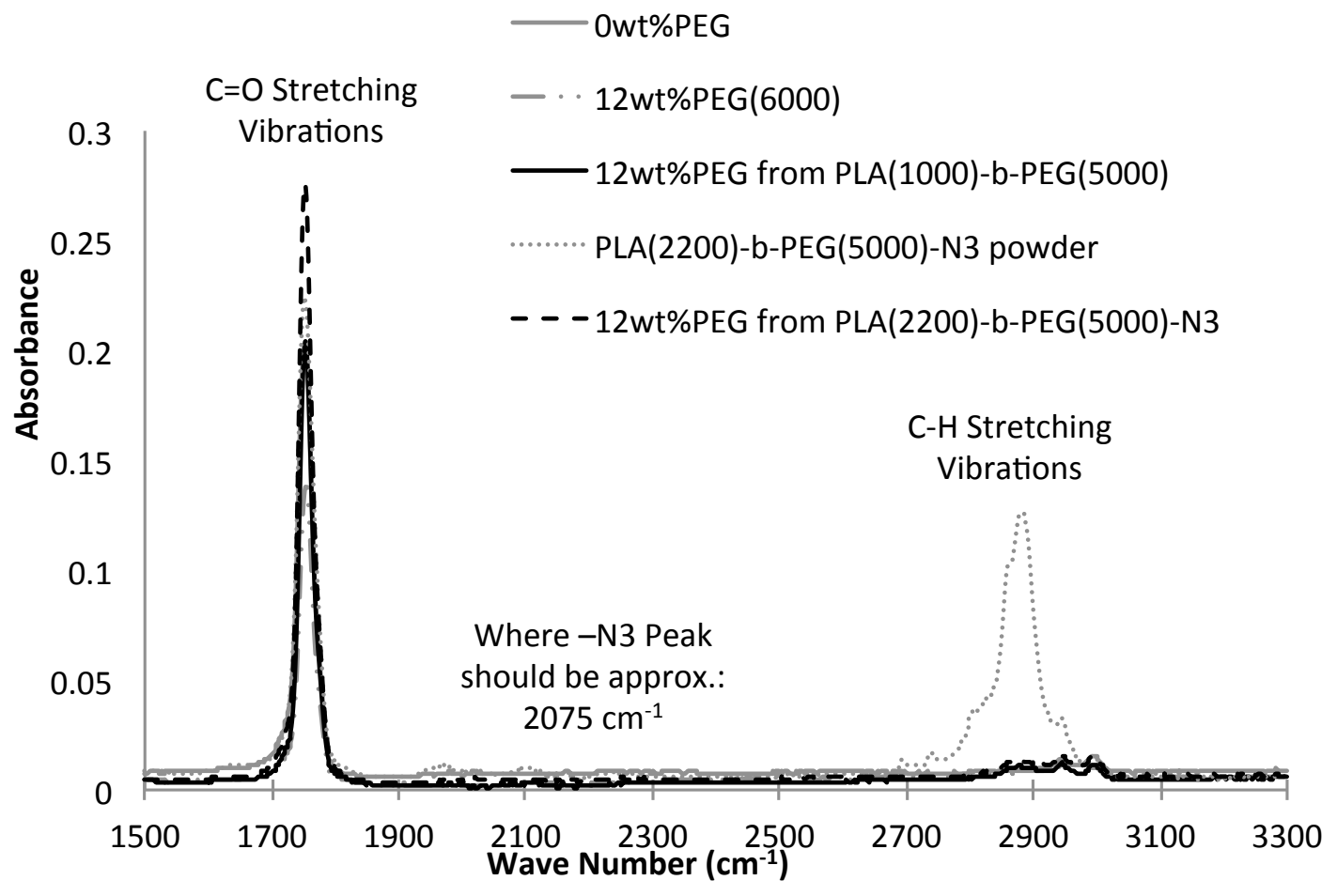

Figure 19. FTIR data for $0 w t \% P E G$, PLA/PLA-b-PEG, and PLA/PLA-b-PEG-N3 fibers.

iv. Tof-SIMS

Time of Flight Secondary Ion Mass Spectrometry (Tof-SIMS) example data collected by EAGLabs is shown in Figure 20. The values plotted were a ratio of $\mathrm{m} / \mathrm{z} 45$ and $\mathrm{m} / \mathrm{z} 56$. This ratio was taken as there was no $\mathrm{m} / \mathrm{z} 44$ peak present in the copolymer samples, which would indicate conclusively that PEG was present. An example of the peaks that were compared are indicated by dashed rectangles and are shown in Figure 20. 

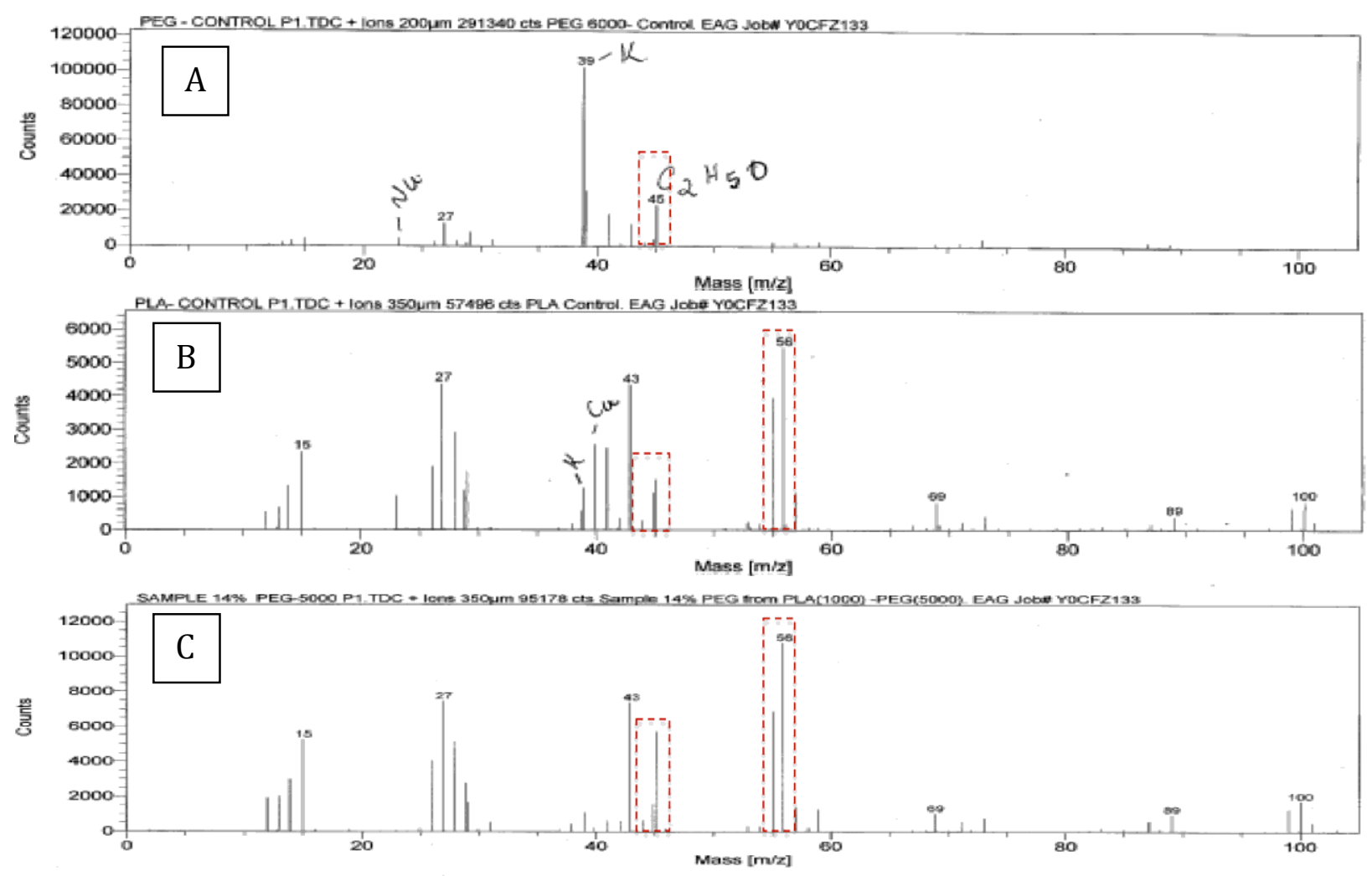

Figure 20. Tof-SIMS data collection. (A) PEG(6000) powder (B) 0wt\%PEG fibers (100wt\%PLA), (C) 14wt\%PEG from PLA(1000)-b-PEG(5000) fibers.

A comparison of the results is shown in Figure 21 where there appears to be a plateau after 10wt\% PEG from PLA(1000)-b-PEG(5000). Comparing with data collected from DSC, at 10wt\%PEG from PLA(1000)-b-PEG(5000) began to phase separate, which is consistent with when the plateau in the Tof-SIMS data begins. This is therefore an indication of when PEG is beginning to phase separate. 12wt\% PEG from PEG(6000) and PEG(1000)-PEG(5000) were determined to be outliers, and may be the result of the small sampling area of the non-woven mat. 


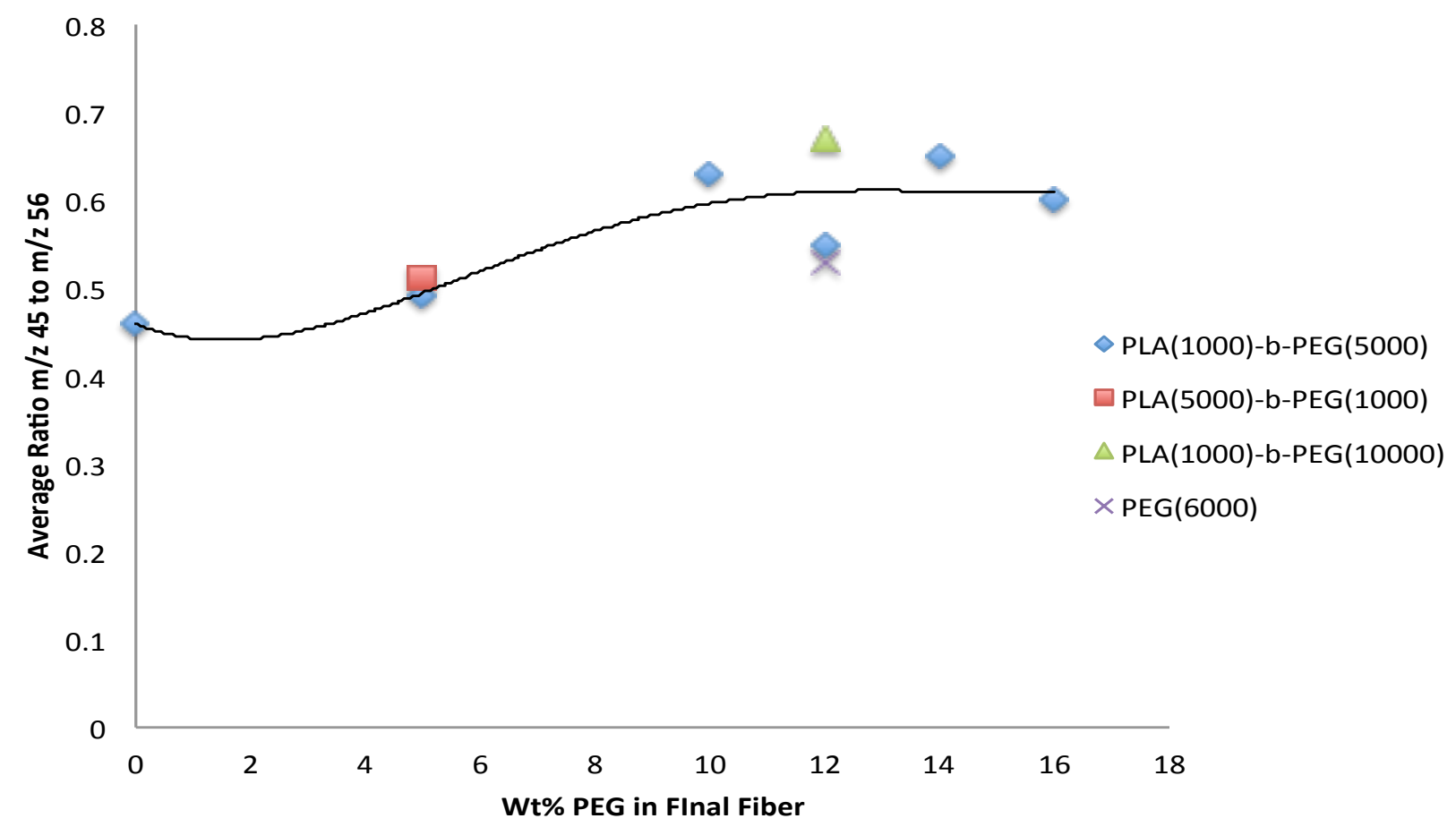

Figure 21. Tof-SIMS ratios compared.

\section{v. Swelling Comparisons}

Fiber fabrics did not change in dimension before and after swelling, remaining $1 \mathrm{~cm} \times 1 \mathrm{~cm}$, thus confirming the fiber is non-water soluble with the addition of the copolymer PLA-b-PEG. Although the non-woven mats containing PLA-b-PEG maintained their dimensions, the fibers began to swell. SEM and pictures taken after the nanofibers had been in direct contact with DIwater for ten minutes are shown in Figure 22. 


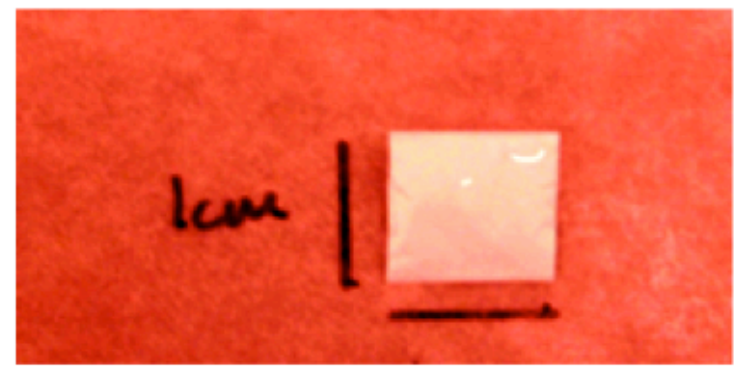

$10 \mathrm{wt} \%$ PEG (6000)

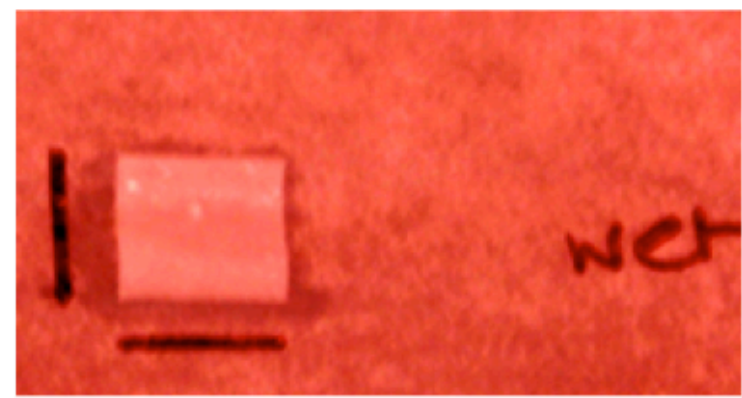

10 wt\% PEG from PLA(1000)b-PEG(5000)

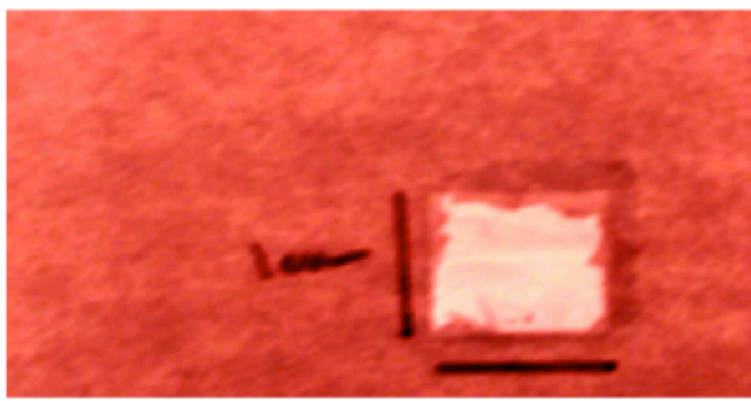

10 wt $\%$ PEG from PLA(1000)-bPEG(10000)

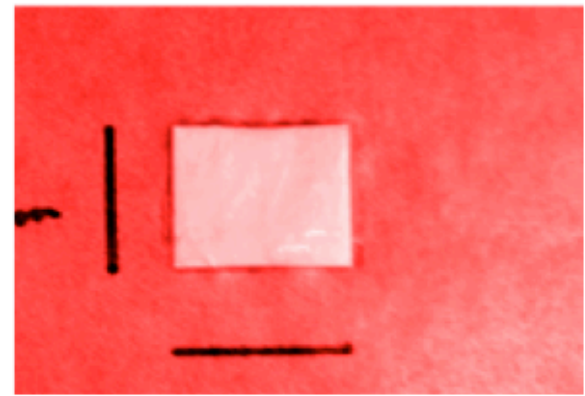

0 wt $\%$ PEG
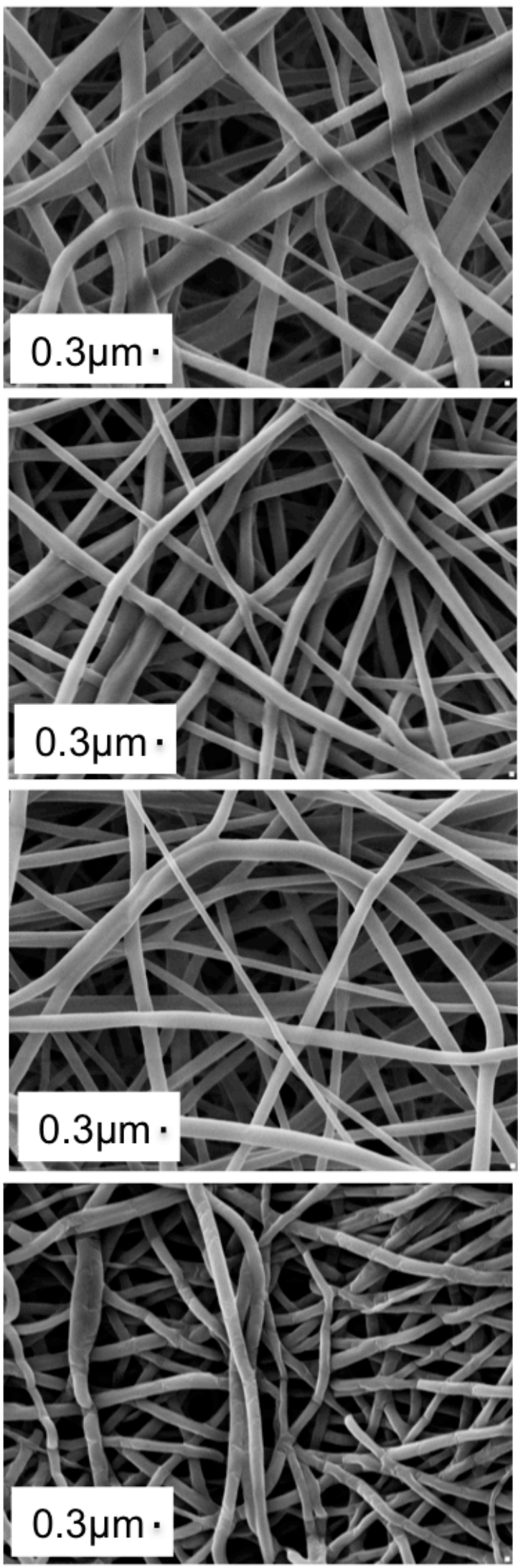

Figure 22. Pictures and SEM images taken post swelling test. 
10wt\% PEG(6000), 10wt\% PEG from PLA(1000)-b-PEG(5000), and 10wt\% PEG from

PLA(1000)-b-PEG(10000) all had a diameter increase after the swell test of 51\%, 49\%, and $18 \%$ respectively. The $0 \mathrm{wt} \% \mathrm{PEG}$ fibers showed a decrease in diameter of $18 \%$. Figure 23 shows the fiber diameters prior and post swell tests. A decrease of PLA electrospun fiber diameter when spun onto a water reservoir was observed by H.S. Kim et al.[67] S.M. Berry et al. found in films of PLLA-PE- PLLA, the PLLA domains shrunk in the presence of water, due to its hydrophilic nature.[68]

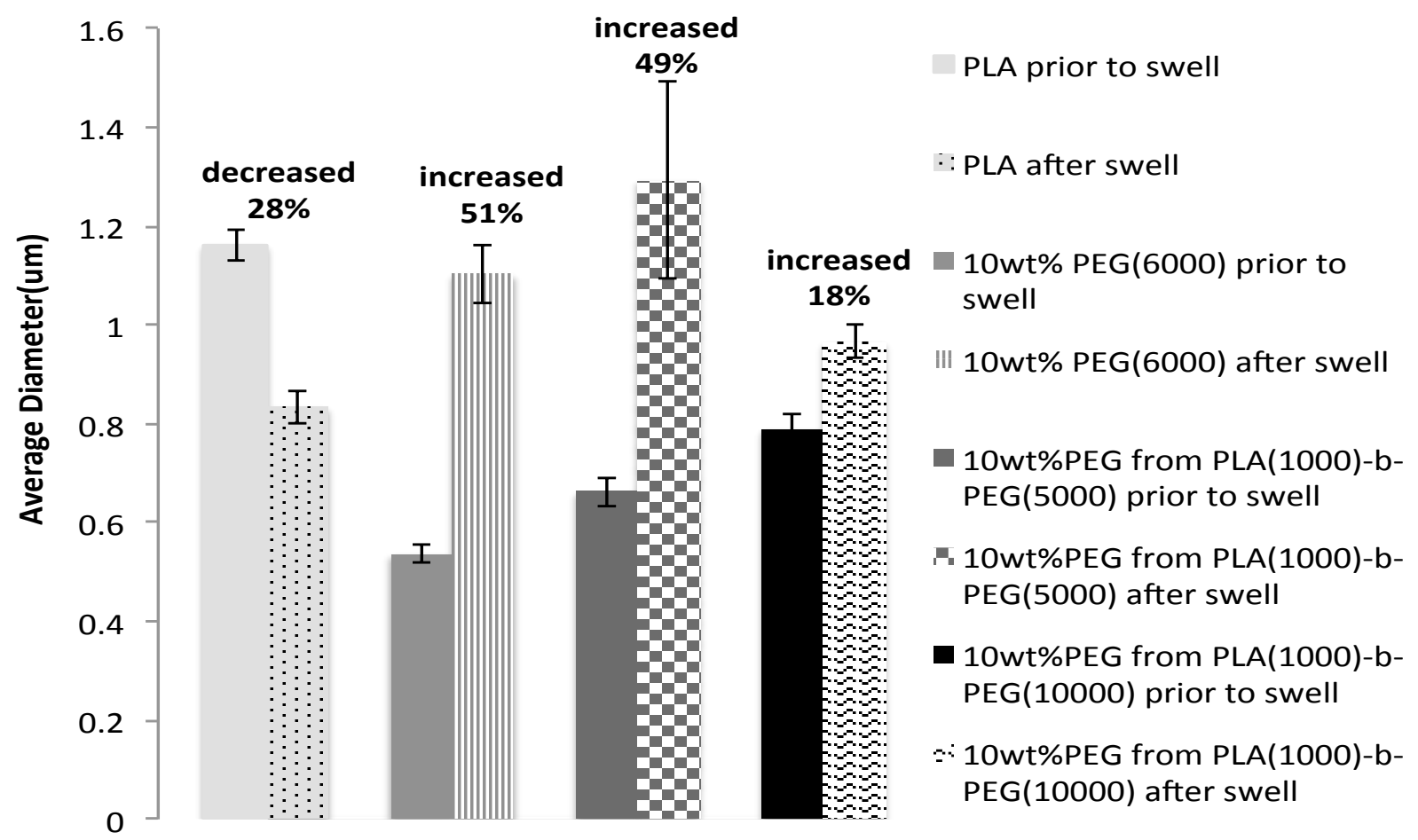

Figure 23. Fiber diameters prior to and after swell test.

\section{vi. Wettability}

With the addition of PLA-b-PEG the PLA fibers are becoming more hydrophilic. The wettability of the fibers is a factor of three components: diameter, pore size, and surface chemistry. [33] M. Rebovich et al. found that a decrease in diameter leads to a decrease in pore size, which increased the capillary action of the non-woven mat.[6] Larger fiber diameter fibers whose 
wettability is greater than the smaller diameter fibers can be attributed to more PEG reaching the fiber surface, thereby overcoming the reduced capillary action inherent of larger fibers.[33] A comparison of the wettability gathered is shown in Figure 24.

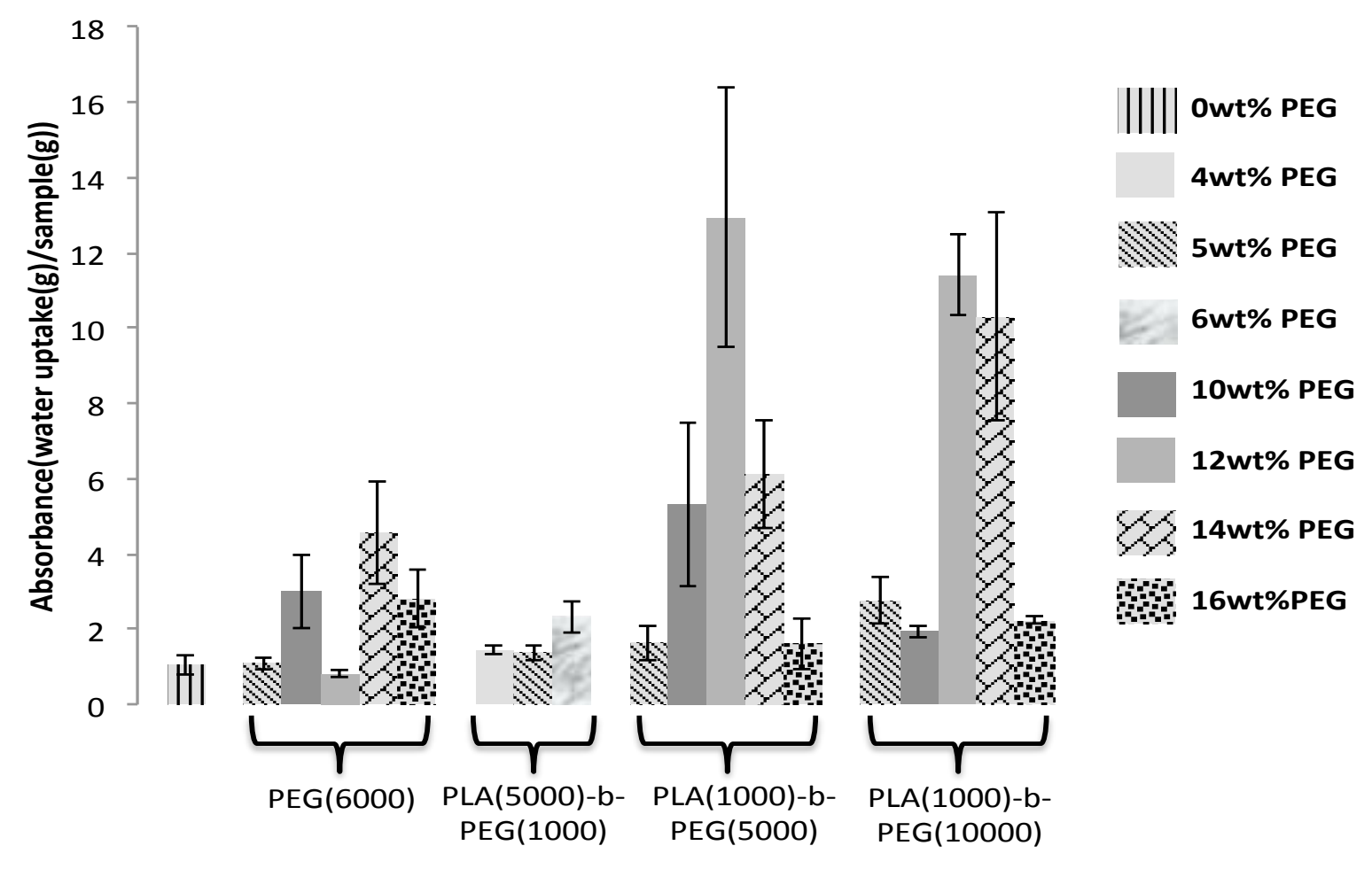

Figure 24. Comparisons of wettability of all fibers produced.

When comparing to DSC results, phase separation of the PEG is seen starting at $10 \mathrm{wt} \%$ PEG for PLA(1000)-PEG(5000). This phase separation corresponds well with the wettability data, where at $10 \mathrm{wt} \%$ PEG from PLA(1000)-b-PEG(5000) there is a significant increase in water uptake. 10wt\%PEG from PLA(1000)-b-PEG(10000) however doesn't phase separate to the surface as much as PLA(1000)-b-PEG(5000) at 10wt\% PEG, as indicated by the DSC, wettability, and water swelling results. PEG(6000) and PLA(5000)-b-PEG(1000) showed the least wettability at all PEG loadings. As copolymer block length was increased, there was an increase in fiber wettability. This suggests that the block lengths of PEG and $\mathrm{wt} \%$ of PEG present are both 
important factors in driving PEG to the fiber surface. Although PEG is phase separating as determined by previous analysis, wettability confirms PEG is not always going to the fiber surface. 12wt\%PEG from PLA(1000)-b-PEG(5000) and 12-14wt $\%$ PEG from PLA(1000)-bPEG(10000) were found to have the greatest wettability and were statistically similar in water uptake.

\section{Conclusions}

Additions of up to $16 \mathrm{wt} \%$ PEG could be incorporated into the fibers by the addition of the heating element and heat gun. With the addition of PLA-b-PEG, fiber diameter decreases significantly when compared to that of the control PLA fibers. This is the result of changing viscosity, and molecular weight. PEG is a plasticizing agent, that increases the crystallizability of PLA. PEG(6000) plasticizes PLA more efficiently than the copolymers, significantly decreasing fiber diameter. For copolymers, as PEG block length increases, there is a decrease in the plasticizers ability, and thus an increase in viscosity. At higher $\mathrm{wt} \%$ solutions, viscosity visually increases, and PEG is no longer acting as an efficient plasticizer. This results in an increase of fiber diameter. At loadings greater than $10 \mathrm{wt} \%$ PEG from PLA-b-PEG, phase separation occurs. PLA fibers are not hydrophilic, but with the addition of the block copolymers, the fibers began to show an increase in hydrophilic nature. Although PEG was phase separating as determined by previous analysis, wettability confirms PEG is not always going to the fiber surface. With increasing chain length of PEG water wicking increases. Based on this, future work future work in contamination/disease capture can be done by functionalizing the $-\mathrm{OH}$ group of the PEG, or by changing its surface charge. 


\section{Future Work}

Cytotoxic drugs are commonly used in the treatment of cancer. These drugs are delivered in a number of ways, but when they are excreted from the body, they end up in ground water supplies, soil, and even sewage treatment plants (STPs).[69-71] This is a major cause of concern because although the cytotoxic drugs help to fight cancer in patients, they have been found to be very cancerous to others at low dosages, and even cause birth defects, and immune dysfunction.[69, 71] The main problem that exists is that when cytotoxic drugs enter into the Sewage Treatment Plants (STPs), the contamination could go undetected due to a low detection limit and/or low dosages.[70] Therefore, it is important that these drugs be captured.

The PLA/PLA-b-PEG investigated in this research have the potential to be functionalize, and used as nanofiber filters for capture of specific cytotoxic contaminations in water supplies. Nanofiber membranes are ideal for filtration/capture due to their high surface areas.[72] Fiber surface charge can provide the necessary chemistry for successful filtration/capture of molecules with opposite charge from the fiber.[72-74] Matlock-Colangelo et al. showed that electrospun fibers could be functionalized and used in microfluidic devices.[73] Here the fibers were used to detect liposomes present within a media. The liposomes were attracted to a fiber with the opposite charge, and repelled the fibers with the same charge as the liposomes. It has been found that by adding nanoscale materials directly to the spinning dope, surface chemistry of the nanofibers could be altered. This could be achieved by the functional group (-OH) of the PEG being either protonated or ionized and the ions of opposite charge being attracted to it. Cho et al. found that the zeta potential measurements are important in determining the fibers' surface charges[72] which would be responsible for the adhesion of cytotoxic drugs to the nanofibers. 


\section{References:}

1. A.M. Rossi, L.W., V. Reipa, T.E. Murphy, Porous Silicon Biosensor fo Detection of Viruses. Biosensors and Bioelectronics, 2007. 23: p. 741-745.

2. Nadeau, J., Editorial: Nanotechnological Advances in Biosensors. Sensors, 2009. 9: p. 8907-8910.

3. Q. P. Pham, A.G.M., Electrospinning of Polymeric Nanofibers for Tissue Engineering Applications: A Review. Tissue Engineering. Tissue Engineering, 2006. 12(5): p. 1197-1211.

4. Ping Lu, B.D., Applications of Electrospun Fibers. Recent Patents on Nanotechnology, 2008. 2: p. 169182.

5. Li, D.P., M.W. Frey, and Y.L. Joo, Characterization of nanofibrous membranes with capillary flow porometry. Journal of Membrane Science, 2006. 286(1-2): p. 104-114.

6. Rebovich, M.E., D. Vynias, and M.W. Frey, Formation and functions of high-surface-area fabrics. International Journal of Fashion Design, Technology and Education, 2010. 3(3): p. 129 - 134.

7. Kim, C.W., et al., Preparation of submicron-scale, electrospun cellulose fibers via direct dissolution. Journal of Polymer Science Part B-Polymer Physics, 2005. 43(13): p. 1673-1683.

8. Li, D.P., M.W. Frey, and A.J. Baeumner, Electrospun polylactic acid nanofiber membranes as substrates for biosensor assemblies. Journal of Membrane Science, 2006. 279(1-2): p. 354-363.
9. Frey, M.W., et al., Incorporation of biotin into PLA nanofibers via suspension and dissolution in the electrospinning dope. Journal of Biobased Materials and Bioenergy, 2007. 1(2): p. 220-228.

10. Li, D., et al., Availability of biotin incorporated in electrospun PLA fibers for streptavidin binding. Polymer, 2007. 48(21): p. 63406347.

11. Xiang, C.H., et al., Selective chemical absorbance in electrosupun nonwovens. Journal of Applied Polymer Science, 2007. 106(4): p. 2363-2370.

12. Xiang, C.H., Y.L. Joo, and M.W. Frey, Nanocomposite Fibers Electrospun from Poly(lactic acid)/Cellulose Nanocrystals. Journal of Biobased Materials and Bioenergy, 2009. 3(2): p. 147-155.

13. Buyuktanir, E.A., M.W. Frey, and J.L. West, Self-assembled, optically responsive nematic liquid crystal/polymer core-shell fibers: Formation and characterization. Polymer, 2010. 51(21): p. 48234830.

14. Hendrick, E., et al., Cellulose Acetate Fibers with Fluorescing Nanoparticles for Anti-counterfeiting and $\quad$ H-sensing Applications. Journal of Engineered Fibers and Fabrics, 2010. 5(1): p. 21-30.

15. Li, L. and M. Frey, Preparation and characterization of cellulose nitrateacetate mixed ester fibers. Polymer, 2010. 51(16): p. 3774-3783.

16. Buyuktanir, E.A., J.L. West, and M.W. Frey, Optically responsive liquid crystal microfibers for display 
and nondisplay applications. Proc. SPIE, 2011. 7955: p. 79550P.

17. Cho, D., et al., Properties of PVA/HfO2 Hybrid Electrospun Fibers and Calcined Inorganic HfO2 Fibers. The Journal of Physical Chemistry C, 2011. 115(13): p. 5535-5544.

18. Cho, D., N. Hoepker, and M.W. Frey, Fabrication and characterization of conducting polyvinyl alcohol nanofibers. Materials Letters, 2012. 68(0): p. 293-295.

19. Cho, D., S. Lee, and M.W. Frey, Characterizing zeta potential of functional nanofibers in a microfluidic device. Journal of Colloid and Interface Science, 2012. 372(1): p. 252-260.

20. Cho, Y., et al., Preparation and Characterization of Amphiphilic Triblock Terpolymer-Based Nanofibers as Antifouling Biomaterials. Biomacromolecules, 2012. 13(5): p. 1606-1614.

21. K. Madhavan Nampoothiri, N.R.N., Rojan Pappy John, An Overview of the Recent Developments in Polylactide (PLA) Research. Bioresource Technology, 2010. 101(22): p. 8493-8501.

22. Xiang, C., et al., Controlled release of nonionic compounds from poly(lactic acid)/cellulose nanocrystal nanocomposite fibers. Journal of Applied Polymer Science, 2012: p. n/a-n/a.

23. Asli, M.M., B. Pourdeyhimi, and E.G. Loboa, Release Profiles of Tricalcium Phosphate Nanoparticles from Poly(L-lactic acid) Electrospun Scaffolds with Single Component, Core-Sheath, or Porous Fiber Morphologies: Effects on hASC Viability and Osteogenic
Differentiation. Macromolecular Bioscience, 2012. 12(7): p. 893-900.

24. $\mathrm{Hu}, \mathrm{H}$, et al., Synergic effect of magnetic nanoparticles on the electrospun aligned superparamagnetic nanofibers as a potential tissue engineering scaffold. Rsc Advances, 2013. 3(3): p. 879886.

25. Kim, E.S., S.H. Kim, and C.H. Lee, Electrospinning of polylactide fibers containing silver nanoparticles. Macromolecular Research, 2010. 18(3): p. 215-221.

26. Song, B.T., C.T. Wu, and J. Chang, Controllable delivery of hydrophilic and hydrophobic drugs from electrospun poly(lactic-co-glycolic acid)/mesoporous silica nanoparticles composite mats. Journal of Biomedical Materials Research Part B-Applied Biomaterials, 2012. 100B(8): p. 2178-2186.

27. Chen, S.C., et al., The Influence of Fiber Diameter of Electrospun Poly(lactic acid) on Drug Delivery. Fibers and Polymers, 2012. 13(9): p. 1120-1125.

28. Thuy, T.T.N., et al., Porous core/sheath composite nanofibers fabricated by coaxial electrospinning as a potential mat for drug release system. International Journal of Pharmaceutics, 2012. 439(1-2): p. 296-306.

29. Wei, K., et al., Fabrication of coresheath structured fibers for model drug release and tissue engineering by emulsion electrospinning. Biotechnology Journal, 2012. 7(5): p. 677-685.

30. Kriel, H., R.D. Sanderson, and E. Smit, Coaxial Electrospinning of Miscible PLLA-Core and PDLLAShell Solutions and Indirect 
Visualisation of the Core-Shell Fibres Obtained. Fibres \& Textiles in Eastern Europe, 2012. 20(2): p. 28-33.

31. Gupta, K.K., et al., Hydrothermal in situ preparation of $\mathrm{TiO} 2$ particles onto poly(lactic acid) electrospun nanofibres. Applied Surface Science, 2013. 264: p. 375-382.

32. Meng, Z.X., et al., Immobilizing natural macromolecule on PLGA electrospun nanofiber with surface entrapment and entrapment-graft techniques. Colloids and Surfaces BBiointerfaces, 2012. 94: p. 44-50.

33. Hendrick, E., in Fiber Science \& Apparel Design2011, Cornell University: Ithaca.

34. Hendrick, E., INCREASING SURFACE HYDROPHILICITY IN POLY(LACTIC ACID) ELECTROSPUN FIBERS BY $A D D I T I O N$ OF PLA-b-PEG COPOLYMERS Journal of Engineered Fibers and Fabrics, 2013.

35. É Kissa, I.B., E.I. Vargha-Butlerc, XPS and Wettability Characterization of Modified Poly(lactic acid) and Poly(lactic/glycolic acid) Films. Journal of Colloid and Interface Science, 2002. 245(1): p. 91-98.

36. M. Zhang, X.H.L., Y.D. Gong, N.M. Zhao, X.F. Zhang, Properties and Biocompatibility of Chitosan Films Modified by Blending with PEG. Biomaterials, 2001. 23: p. 26412648.

37. H. Jiang, Y.H., P.Zhao, Y. Li, K. Zhu, Modulation of Protein Release from Biodegradable Core-Shell

Structured Fibers Prepared by Coaxial Electrospinning. Journal of Biomedical Materials Research Part B: Applied Biomaterials, 2005. 79B(1): p. 50-57.
38. B. Gupta, M.K., S. Hudson, E. Loboa, R. Hufenus, J.Gluck, A. Moghe, Electrospun Core-Sheath Fibers for Soft Tissue Engineering, N.T. Center, Editor 2005.

39. Wei, M., Kang, B., Sung, C. and Mead, J, Core-Sheath Structure in Electrospun Nanofibers from Polymer Blends. Macromolecular Materials and Engineering, 2006. 291: p. 1307-1314.

40. A. Saraf, G.L., A. Haesslein, F. Kurtis Kasper,R. M. Raphael, L. Scott Baggett, and A. G. Mikos, Fabrication of Nonwoven Coaxial Fiber Meshes by Electrospinning. Tissue Engineering: Part C, 2008. 15(3): p. 333-344.

41. Hannappel, J.E., Nanomanufacturing and Analysis of Novel Integrated Continuous Nanofibers, in Engineering Mechanics2010, Graduate College at the University of Nebraska: Lincoln.

42. Zhou, F.-L., Gong, R.-H. and Porat, I. , Mass production of nanofibre assemblies by electrostatic spinning. Polymer International, 2009. 58: p. 331-342.

43. A. Kumar, M.W., C.Barry, J. Chen, J.Mead, Controlling Fiber Repulsion in Multijet Electrospinning for Higher Throughput. Macromolecular Materials and Engineering, 2010. 295(8): p. 701-708.

44. A. Varesano, F.R., G. Mazzuchetti, C.Tonin, R. Comotto Multi-Jet Nozzle Electrospinning on Textile Substrates: Observations on Process and Nanofibre Mat Deposition. Polymer International, 2010. 59(12).

45. N. M. Thoppey, J.R.B., L. I. Clarke, R. E. Gorga, Edge Electrospinning for High Throughput 
Production of Quality Nanofibers. Nanotechnology, 2011. 22(34): p. 111.

46. Y. Liu, L., Dong, J. Fan, R. Wang, J.-Yong $\mathrm{Yu}$, Effect of Applied Voltage on Diameter and Morphology of

Ultrafine Fibers in Bubble Electrospinning. Journal of Applied Polymer Science, 2010. 20(1): p. 592-598.

47. D. Lukas, A.S., L. Martinova, K. Vodsed'alkova, D. Lubasova, J. Chaloupek, P. Pokorny, P. Mikes, J. Chvojka, M. Komarek, Physical Principles of Electrospinning (Electrospinning as a

Nano-scale Technology of the Twenty-first Century). Textile Progress, 2009. 41(2): p. 59-140.

48. R. A. L. Jones, R.W.R., Polymers at Surfaces and Interfaces, 2006, Cambridge University Press: New York.

49. S. M. Li, I.R., J. L. Espartero, N. M. Vert Manolova, Synthesis, Characterization, and Hydroplytic Degradation of PLA/PEO/PLA Triblock Copolymers with Long Poly(L-Lactic Acid) Blocks. Macromolecules, 1996. 29: p. 57-62.

50. H. Hatakeyama, T.H., Interaction Between Water and Hydrophilic Polymers. Thermochimica. Thermochimica, 1998. 308: p. 3-22.

51. H. Lin, B.D.F., Gas Solubility, Diffusivity and Permeability in Poly(Ethylene Oxide). Journal of Membrane Science, 2003. 239: p. 105-117.

52. Y. Esakaa, S.I., D. Uchidaa, M. Gotoa, K. Kanob, Polyacrylamides as Hydrophilic Selectors in NonAqueous Capillary Electrophoresis. Journal of Chromatography A, 2001. 905: p. 291-297.
53. Harris, J.M., Polyetheylene GlycolBiotechnology. 1992, New York: Plenum Press.

54. A. Keller, S.C., The Role of Metastability in Polymer Phase Transitions. Polymer, 1998. 39(19): p. 4461-4487.

55. S. Puvvada, D.B., Thermodynamic Description of Micellization, Phase Behavior, and Phase Separation of Aqueous Solutions of Surfactant Mixtures. J. Phys. Chem, 1992. 96(13): p. 5567-5579.

56. H. Takeshita, K.F., T. Ohnishi, T. Ohkubo, M. Miya, K. Takenaka, T. Shiomi, Formation of Lamellar Structure by Competition in Crystallization of Both Components for Crystalline-Crystalline Block Copolymers. Polymer, 2006. 47(24): p. 8210-8218.

57. J.M. Deitzel, J.K., D. Harris, N.C. Beck Tan, The effect of processing variables on the morphology of electrospun nanofibers and textiles. Polymer, 2001. 42: p. 261-272.

58. H.Li, M.A.H., Effect of nucleation and plasticization on the crystallization of poly(latic acid). Polymer, 2007. 48: p. 6855-6866.

59. Sungsanit, K., Rheological and Mechanical Behavior of Poly(Lactic Acid)/Polyethylene Glycol Blends, in M. Eng.2011, RMIT University.

60. G. Ozkoc, S.K., Morphology, Biodegradability, Mechanical, and Thermal Properties of Nanocomposite Films Based on PLA and Plasticized PLA. Journal of Applied Polymer Science, 2009. 114: p. 2481-2487.

61. K.Sungsanit, N.K., S.N. Bhattacharya, Properties of Linear Poly(Lactic Acid)/Polyethylene Glycol Blends. Polymer Engineering and Science, 2012. 52: p. 108-116. 
62. Z. Kulinski, E.P., K. Gadzinowska, M. Stasiak, Plasticization of Poly $(L-$ Lactide) with Poly(propylene glycol). Biomacromolecules, 2006. 7: p. 2128-2135.

63. Y. Hu., Y.S.H., V. Topolkaraev, A. Hiltner, E. Baer, Crystallization and phase separation in blends of high stereoregular poly(lactide) with polye(ethylene glycol). Polymer, 2003. 44: p. 5681-5689.

64. P. Pan, W.K., B. Zhum T. Dong, Y. Inoue, Polymorphous Crystallization and Multpile Melting Behavior of Poly(L-lactide): Molecualr Weight Dependence. Macromolecules, 2007. 40: p. 6898-6905.

65. T. Tábi, I.E.S., F. Szabó, A. S. Luyt, J. G. Kovács, Crystalline Structure of Annealed Polylactic Acid and its Relation to Processing. eXPRESS Polymer Letters, 2010. 4(10): p. 659668.

66. X. Zhang, X.H., L. Chen and Y. Zhang, Boronic acid modified magnetic nanoparticles for enrichment of glycoproteins via azide and alkyne click chemistry. Journal of Materials Chemistry, 2012. 22(32): p. 16520-16526.

67. H.S. Kim, K.K., H.J. Jin I.Chin, Morphological characterization of electrospun nano-fibrous membranes of biodegradable poly(L-lactide) and poly(lactide-co-glycolide).

Macromol. Symp., 2005. 224: p. 145-154.

68. S.M. Berry, S.P., J.L.Fernandes, J.M. Rathfon, K.A. Aamer, G. N. Tew, A.S. Gobin, R. W. Cohn, R.S. Keyton, Brush-On Fabrication of Suspended PLLA-PEO-PLLA Triblock Copolymer Fibers,
University of Louisville \& University of Massachusetts

69. Pharma-Cycle. 2012 11/15/2012]; Available from: http://www.pharmacycle.com/.

70. C. D. Metcalfe, B.G.K., D. T. Bennie, M. Servos, T. A.Ternes, R. Hirsch, OCCURRENCE OF NEUTRAL AND ACIDIC DRUGS IN THE EFFLUENTS OF CANADIAN SEWAGE TREATMENT PLANTS. Environmental Toxicology and Chemistry, 2003. 22(12): p. 28722880.

71. N. C. Rowney, A.C.J., R. J. Williams, CYTOTOXIC DRUGS IN DRINKING WATER: A PREDICTION AND

RISK ASSESSMENT EXERCISE FOR THE THAMES CATCHMENT IN THE UNITED KINGDOM. Environmental Toxicology and Chemistry, 2009. 28(12): p. 27332743.

72. D. Cho, S.L., M. W. Frey, Characterizing zeta potential of functional nanofibers in a microfluidic device. Journal of Colloid and Interface Science, 2012 372: p. 252-260.

73. L. Matlock-Colangelo, D.C., C. L. Pitner, M. W. Frey and A. J. Baeumner, Functionalized electrospun nanofibers as bioseparators in microfluidic systems. Lab on a Chip, 2012. 12: p. 1696-1701.

74. D. Cho, L.M.-C., C. Xiang , P. J. Asiello, A. J. Baeumner, M. W. Frey, Electrospun nanofibers for microfluidic analytical systems. Polymer, 2011. 52: p. 3413-3421. 